devenir Vol. 3, N5, ENERO - JUNIO 2016, PP. 67-89 - ESTUDIOS IISSN 2312-7570 UNIVERSIDAD NACIONAL DE INGENIERÍ, LIMA

\title{
RENOVACIÓN URBANA Y CENTRO HISTÓRICO DE LIMA: REFLEXIONES SOBRE ASPECTOS TÉCNICOS EN LA RECONFIGURACIÓN MORFOLÓGICA DE LAS MANZANAS 6007 Y 6016 DE BARRIOS ALTOS ${ }^{[*]}$
}

\author{
URBAN RENEWAL AND THE HISTORIC CENTER OF LIMA: THOUGHTS ABOUT TECHNICAL \\ ASPECTS OF THE MORPHOLOGIC RECONFIGURATION OF THE 6007 AND 6016 \\ BLOCKS OF BARRIOS ALTOS
}

ANTONIO MIGUEL ÁLVAREZ REÁTEGUl ${ }^{(\star \star)} Y$ FREDY JHON MENDOZA NÚÑEZ $Z^{[\star \star *]}$

Fecha de recepción: 04 de abril de 2016

Fecha de aprobación: 24 de mayo de 2016

\section{RESUMEN}

El Centro Histórico de Lima es el área fundacional y central del actual tejido urbano de Lima Metropolitana; cuenta con una extensión de 239.69 ha., de las cuales Barrios Altos representa 63 ha. (26\%). A pesar de que alberga inmuebles de carácter patrimonial y de mucha importancia en la historia urbana de la ciudad, en la actualidad presenta un alto grado de deterioro social, tugurización y áreas sensibles con riesgos de colapso que afectarían a aproximadamente 4,500 familias.

Esta investigación se centra en dos manzanas representativas de Barrios Altos (de códigos catastrales 6007 y 6016). Partimos del reconocimiento de su historia, su situación crítica expresada en datos cuantitativos, la revisión de normativas para la renovación urbana y la casuística de casos exitosos en ciudades latinoamericanas. Luego, reflexionamos sobre los Lineamientos Básicos Orientadores (L.B.O.) propuestos por la Municipalidad Metropolitana de Lima para la reconfiguración morfológica de ambas manzanas; estos forman parte del proceso de renovación urbana en Barrios Altos en pos de un espacio vivo, dinámico y con mejores condiciones de vida.

\section{PALABRAS CLAVE}

Barrios Altos del Centro Histórico de Lima, renovación urbana, Lineamientos Básicos Orientadores

\section{ABSTRACT}

The Historic Center of Lima is the foundational and current central area of Lima's urban social fabric; it covers an area of 239.69 ha. of which Barrios Altos represents $63 \mathrm{Ha}$. (26\%). Even though it harbors patrimonial estate, very important for the city's urban history, today it presents a high degree of social deterioration, urban blight and sensitive areas, which have a risk of collapse that could affect about 4500 families. The research focuses on two representative blocks of Barrios Altos (Cadastral codes 6007 and 6016). We start from their historical recognition, their critical situation expressed in quantitative data, the review of regulations for urban renewal and the casuistry of successful cases in Latin American cities. It allows us to reflect on the Basic Guidelines (BG) proposed by the Metropolitan Municipality of Lima for the morphological reconfiguration of both blocks; this forms part of urban renewal in Barrios Altos in search of a living, dynamic space and better living conditions.

\section{KEYWORDS}

Barrios Altos of the Historic Center of Lima, urban renewal, Basic Guidelines

(*) El presente artículo retroalimenta y reflexiona sobre una investigación que realizaron los autores por encargo de la dirección del equipo técnico de la Subgerencia de Renovación Urbana de la Gerencia de Desarrollo Urbano de la Municipalidad Metropolitana de Lima durante el año 2014. Esta formó parte de los estudios técnicos del Proyecto de Inversión Pública con Endeudamiento Externo del Banco Interamericano de Desarrollo (BID), en el sector de Barrios Altos del Centro Histórico de Lima. ${ }^{* *}$ ) Arquitecto por la Facultad de Arquitectura, Urbanismo y Artes de la Universidad Nacional de Ingeniería, con estudios de especialización en Gestión de Planes Urbanos por el Colegio de Arquitectos del Perú y en Enseñanza en Educación Superior por Laureate Universities. Se ha desempeñado como docente universitario, jefe de la División Técnica en la Subgerencia de Renovación Urbana, jefe de la División de Edificaciones en la Municipalidad Metropolitana de Lima y subgerente de Obras Privadas en la Municipalidad de Breña. Actualmente cursa una maestría de Docencia Universitaria y es consultor de proyectos arquitectónicos. Contacto: cureperu@hotmail.com

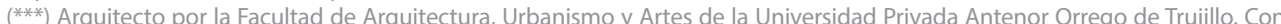
estudios concluidos de Maestría en Renovación Urbana en la Universidad Nacional de Ingeniería. Experto universitario en Desarrollo Local y Turismo por la Universidad de Alicante de España, y la Universidad Nacional Pedro Ruiz Gallo de Lambayeque. Consultor de proyectos arquitectónicos y urbanos. Docente e investigador universitario. Contacto: atutraq@hotmail.com 
devenir Vol. 3, N5, ENERO- JUNIO 2016, PP. 67-89- EsTUDIOS I ISSN 2312-7570

UNIVERSIDAD NACIONAL DE INGENIERÍ, LIMA

\section{Antecedentes históricos de las manzanas 6007 y 6016 en Barrios Altos}

Barrios Altos lleva este nombre por su ubicación en la cota más alta de Lima Virreinal; territorialmente se encuentra emplazado sobre el valle producido por la cuenca hidrográfica del río Rímac, al lado este del Centro Histórico de Lima y del Distrito de Cercado. Se encuentra delimitado al Norte por el río Rímac, al Oeste por la Av. Abancay, al Sur por la Av. Grau y al Este por Jirón José de Rivera y Dávalos. Esto le da actualmente una localización estratégica, situación heredada desde su fundación, con una eficiente conectividad dentro del actual y extenso tejido metropolitano de Lima. Esto se debe a su cercanía al núcleo fundacional y a los sistemas modales de transporte público, así como a la línea del tren eléctrico, el metropolitano y futuros corredores viales.

Barrios Altos es un espacio de importante valor patrimonial, producto de la interacción de diversos factores que se dieron en su entorno inmediato; esto hace necesario comprenderlo no solo desde su dimensión física-espacial sino también "....dentro de un proceso histórico que es esencial estudiar para comprender lo que ha sido, es y puede llegar a ser la ciudad" (Chueca, 1968, p. 24). Además, posee una particular estructura urbana y escala de barrio; estas están determinadas en parte por su escala y entorno monumental pero principalmente por el vínculo interior-exterior de las manzanas que aún mantiene el poblador original, así como por otros factores exógenos.

Por ello, "no podemos decir que esa realidad... corresponde solo a uno de estos ordenes, al físico o al moral, sino a algo que los resume y acoge conjuntamente. Puesto que los contenidos de esta organización física y moral de la ciudad se están ... modelando y modificando uno a otro por su mutua interacción, este fenómeno tiene que

Figura 1. Barrios Altos y su localización a escala metropolitana, distrital y barrial

Fuente: Elaboración Antonio Álvarez y Fredy Mendoza sobre la base de cartografía de la MML, 2016.

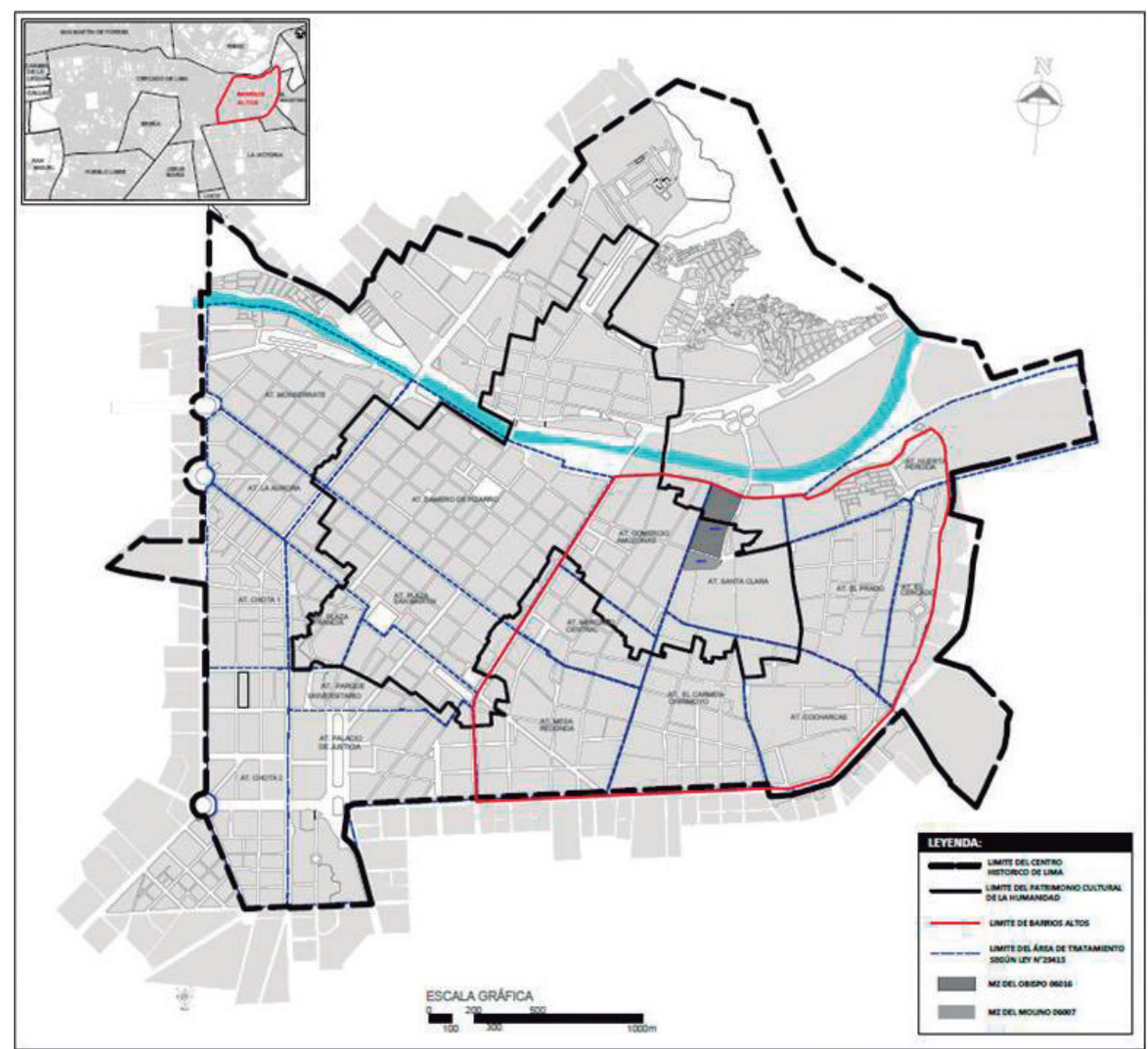


producirse dentro de un ámbito que no puede ser otro que el de la vida de la propia ciudad...." (Chueca, 1968, pp. 30-31). Estas premisas teóricas permiten comprender y determinar que Barrios Altos presenta, a lo largo de su existencia, cuatro periodos marcados y diferenciados en función a su temporalidad, espacialidad y conectividad:

Periodo de preexistencia. En este periodo se consideran dos momentos: el primero, en que los elementos estructurantes eran canales y caminos prehispánicos que se conectaban con otros asentamientos menores y delimitaban algunas plazas irregulares, lo cual conformaba un sistema urbano prehispánico (Gunther, 1983); y un segundo momento que plantea el trazo paulatino, en 55 años, de tres modelos urbanos (Mattos-Cárdenas, 2004). Entre estos modelos, se trazó primero el pragmático, determinado por trazos rectilíneos y ortogonales, realizado por F. Pizarro en 1535; cuenta con calles rectas, manzanas cuadradas y la plaza central, que se mantiene hasta la fecha. En segundo lugar, se dio el modelo bíblico, iniciado en 1571 a partir de dos ejes transversales orientados hacia los cuatro ejes cardinales; estos configuran una trama urbana en forma de cruz donde la plaza central se genera a partir de recortes en diagonal de sus cuatro manzanas centrales, lo que la convierte en zona de uso exclusivo (llamada 'Cercado de Indios') para la mano de obra indígena. Por último, se trazó el modelo jerarquizado en 1590 a partir de un eje principal orientado de norte a sur, el cual tiene como remate visual la iglesia de San Lázaro. Esta etapa es determinante, ya que entonces se establecieron los ejes y principales conexiones que determinarían la estructura urbana y la morfología de lo que hoy conocemos como Barrios Altos.

Periodo intersticial y de conurbación. El primer momento de este periodo está caracterizado por el emplazamiento libre de los primeros monasterios y claustros, el aumento de población y el sobreuso de la vivienda influenciado por la aparición de equipamiento nuevo, así como por la necesidad de mayor mano de obra y servidumbre cercanas al núcleo fundacional. Es decir, Barrios Altos apoya su nacimiento sobre una base física preexistente y ocupa los espacios residuales, o intersticios, entre el trazado de canales -caminos prehispánicos, los nuevos núcleos urbanos y los primeros monasterios respectivamente-. Es en este momento que también se origina la base física y social de los actuales tugurios, ya que "....en el interior de las primeras manzanas que abandonan la subdivisión de 4 solares a un mayor número fomentando el subarriendo y posteriormente la tugurizarían..." (García Bryce, 1980, p. 33). El segundo momento está relacionado directamente con la construcción de la muralla en 1687, con su crecimiento y consolidación intramuros. Además, está vinculado con la pérdida de su unidad espacial urbana y separación física con el Cercado de Indios; hasta ese entonces esta se mantenía transformando radicalmente la estructura urbana.

Periodo de densificación y hacinamiento. Se caracteriza por la demolición de la muralla en 1872 y por las obras de conectividad del Centro de Lima con el borde urbano a través de avenidas, puentes y alamedas; esto ocasionó que la población obrera en Barrios Altos -junto a negros, esclavos, indígenas de la sierra traídos para servicios doméstico y los coolies, quienes culminaban sus periodos laborales $\neg-$ tengan trabajos eventuales. Por ello, las casas patios en el área fundacional de Lima, especialmente en el Cuartel Tercero -corazón de Barrios Altos- se transformaron en casas de arriendo; llegaron en 1906 a más de 130,000 habitantes a 671 callejones y 755 casas de vecindad, las cuales albergaban el $44.7 \%$ de la población limeña total (Ramón, 1999). Además, aparecieron importantes casonas solariegas como la quinta Heeren, las cuales modificaron parcialmente la imagen del barrio.

Periodo de deterioro físico y social. Los principales eventos que promovieron cambios a nivel de su imagen urbana en este periodo fueron el evento sísmico de 1940, la falta de mantenimiento de las edificaciones, y la salida de la clase media y alta, desde 1900, hacia Miraflores, San Isidro y Barranco, en busca de modernidad (De los Ríos, 2007). Además, también se dieron, por un lado, la posterior desintegración del área 


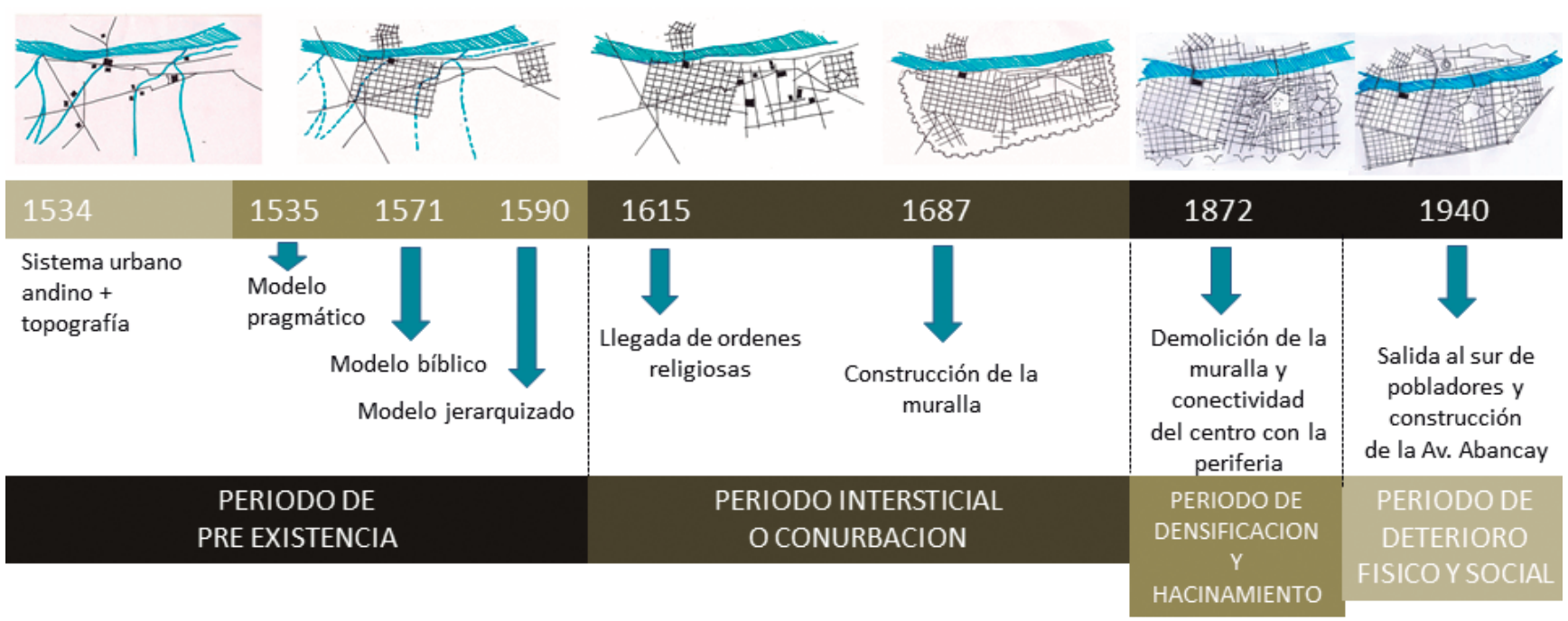

Figura 2. Evolución urbana de Barrios Altos

Fuente: Elaboración Antonio Álvarez y Fredy Mendoza basada en cartografía, 2016. fundacional, debido a la construcción de la Av. Abancay en 1952 y, por otro lado, la llegada de nuevos pobladores en busca de espacios económicos, como parte del proceso migratorio del interior del país hacia Lima que se dio desde 1940 (ver Figura 2).

Internamente la configuración urbana de Barrios Altos tiene como principales elementos estructurantes en la orientación oeste-este los caminos prehispánicos que salían del área fundacional rumbo a la Molina y Huarochirí. Hoy los conocemos como el Jr. Junín y el Jr. Ancash, el cual tiene un trazo paralelo al río Rímac; ambos caminos-jirones se constituyen como los ejes de conexión y continuación espacial con el Cercado de Indios. Asimismo, en la orientación norte-sur el canal Huatica es determinante para el trazo de las principales manzanas desde el Jr. Amazonas y el Jr. Jauja hasta el Jr. Huanta, y llega incluso a delimitar la lotización interna de la actual manzana 6015 (entre los jirones Ancash, Paruro, Huanta y Junín). Es así que se configura nuestra área de estudio, las Manzanas 6007 y 6016, también llamadas la Manzana del Obispo y del Molino, respectivamente. La primera debe su nombre a un personaje notable, el Dr. Andrés García de Zurita, Obispo de Trujillo, quien residió en Lima a mediados del siglo XVII ejerciendo el cargo de deán de la Catedral y vicerrector del Colegio Real. La Manzana del Molino se llama así porque en ella funcionaba en un primer momento un antiguo molino que extraía agua del canal Huatica; era propiedad del Hospital de Santa Ana, el cual lo usaba para preparar pan para sus enfermos, y luego fue adquirida por unos migrantes italianos, la familia Rainusso, quienes iniciaron una empresa que mejoró y amplió las antiguas instalaciones del molino (Orrego, 2009).

\section{Situación de las manzanas 6007 y 6016 en el contexto del sector con fi- nanciamiento B.I.D. en Barrios Altos}

El Programa Metropolitano de Vivienda Popular de la Municipalidad Metropolitana de Lima fue creado por Ordenanza 1643-MML (2012); sus objetivos fueron "mejorar las condiciones habitacionales de los sectores populares [...] en el marco de una estrategia de Renovación Urbana" y "promover una densificación habitacional adecuada en zonas urbano-populares...." (p. 481775). El programa Mejoramiento de las Condiciones de Habitabilidad del Centro Histórico de Lima, en un sector de Barrios Altos, Distrito de Lima, Provincia de Lima / Proyecto de Recuperación del Centro Histórico de Lima - PE-LL7-BID (2013) presentó como objetivo el mejoramiento integral de servicios y espacios públicos de una parte de Barrios Altos. En él, se delimitó un sector compren- 
Renovación uRbana y Centro Histórico de Lima:

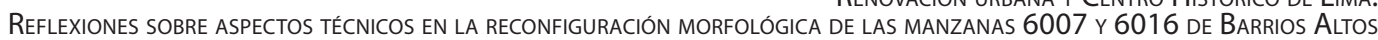

Antonio Álvarez Reátegui y Fredy Mendoza Núñez

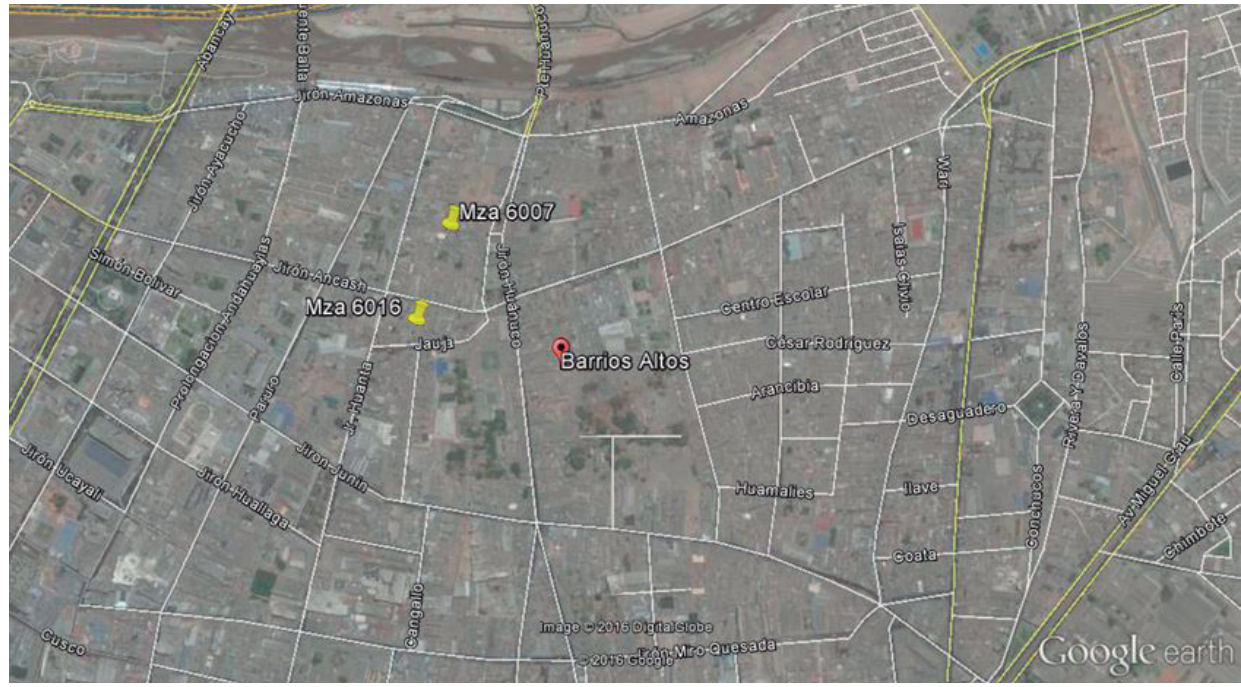

dido entre la Av. Abancay, y los jirones Amazonas, Maynas, Junín, Huanta y Huallaga, el cual destaca por su importante grado de homogeneidad, la ubicación de monumentos de arquitectura civil, doméstica y religiosa, y los inmuebles de valor monumental, así como por su carácter predominante de uso residencial. Este fue delimitado para ser intervenido bajo la gestión de la Municipalidad Metropolitana de Lima con financiamiento del Banco Interamericano de Desarrollo (BID) (ver Figura 6).

Dentro de este sector están emplazadas las manzanas con código catastral 6007 y 6016, las cuales forman parte del Ambiente Urbano Monumental y del Corredor Turístico Monumental - Jr. Ancash; este fue declarado por el Plan Maestro Centro de Lima, aprobado por Ordenanza 201-MML Articulo 37 (1999), y se caracteriza por agrupar la mayor parte de los monumentos y espacios públicos monumentales (ver Figura 7).

Allí, se considera que los objetivos del Plan Maestro Centro de Lima son

....descongestionar y regenerar el tejido urbano de las zonas tugurizadas, propiciando la mejora de condiciones de vida para los pobladores residentes mediante procesos de renovación urbana, [...] regular el uso del suelo a fin de viabilizar las acciones de renovación urbana, alentando la inversión pública y privada en la edificación de viviendas económicas [y] elevar la densidad urbana, intensificando la ocupación y uso del suelo subutilizado.... (1999, p. 172035)

A partir de ello, la presente investigación pretende contribuir con un Centro Histórico que sea vivo y habitable; que permita un mayor reconocimiento efectivo de desarrollo, e incremente la densidad poblacional; que cuente con espacios y áreas libres que otorguen calidad de vida a sus habitantes a través de normativa técnica (Lineamientos y Parámetros Urbanísticos); que regule y sustente el proceso de renovación urbana considerando la situación actual de las manzanas en estudio.

Mediante un análisis de las variables que afectan directamente al proceso de degradación de ambas manzanas, como la monumentalidad, el uso de suelo, la densidad, el área libre, el área verde y la gestión de riesgos, se ha obtenido una serie de estadísticas que reflejan la problemática existente en las dos manzanas seleccionadas.

La manzana 6007 se encuentra en el área declarada como Patrimonio Cultural de la Humanidad y como zona de amortiguamiento; presenta tres inmuebles con categoría de monumento, siete de valor monumental y 44 de entorno. La manzana 6016 se ubica en su totalidad en el área declarada como Patrimonio Cultural de la
Figura 3. Las Manzanas 6007 y 6016 en Barrios Altos

Fuente: Imagen Extraída de Google Earth, 2016 .

Figura 4. El canal Huatica en 1920 Fuente: Archivo fotográfico de Juan Luis Orrego Penagos, 2016.
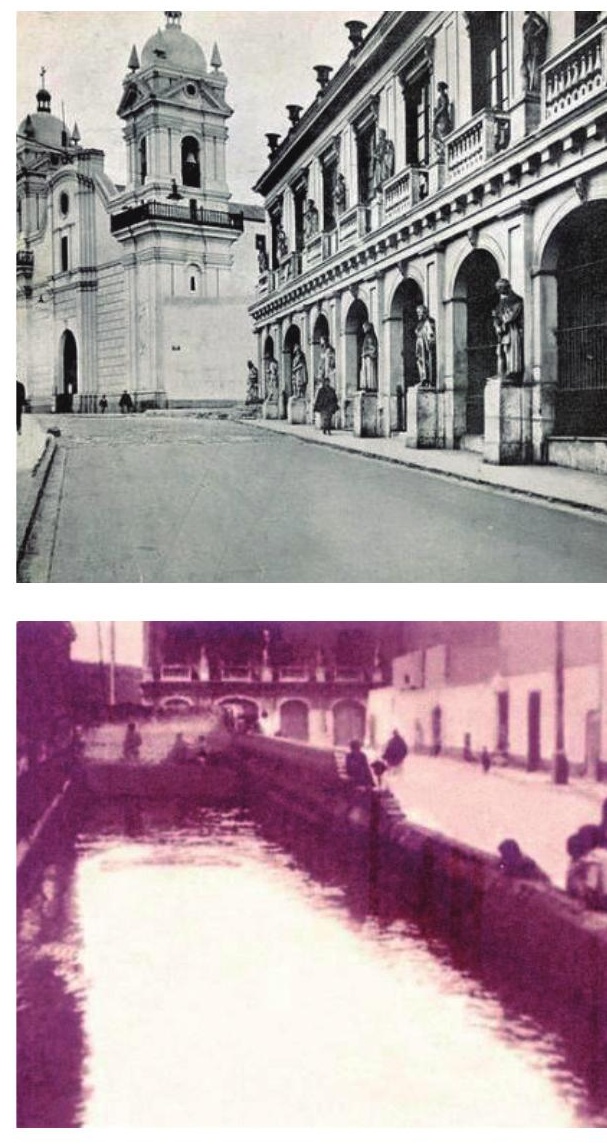

Figura 5. Antiguo molino de Santa Ana

Fuente: Archivo fotográfico de Juan Luis Orrego Penagos, 2016. 
Figura 6. Zona con financiamiento BID

Fuente: Propuesta de lineamientos básicos orientadores (L.B.O.) técnicos para áreas de tratamiento con fines de Renovación Urbana, 2014.

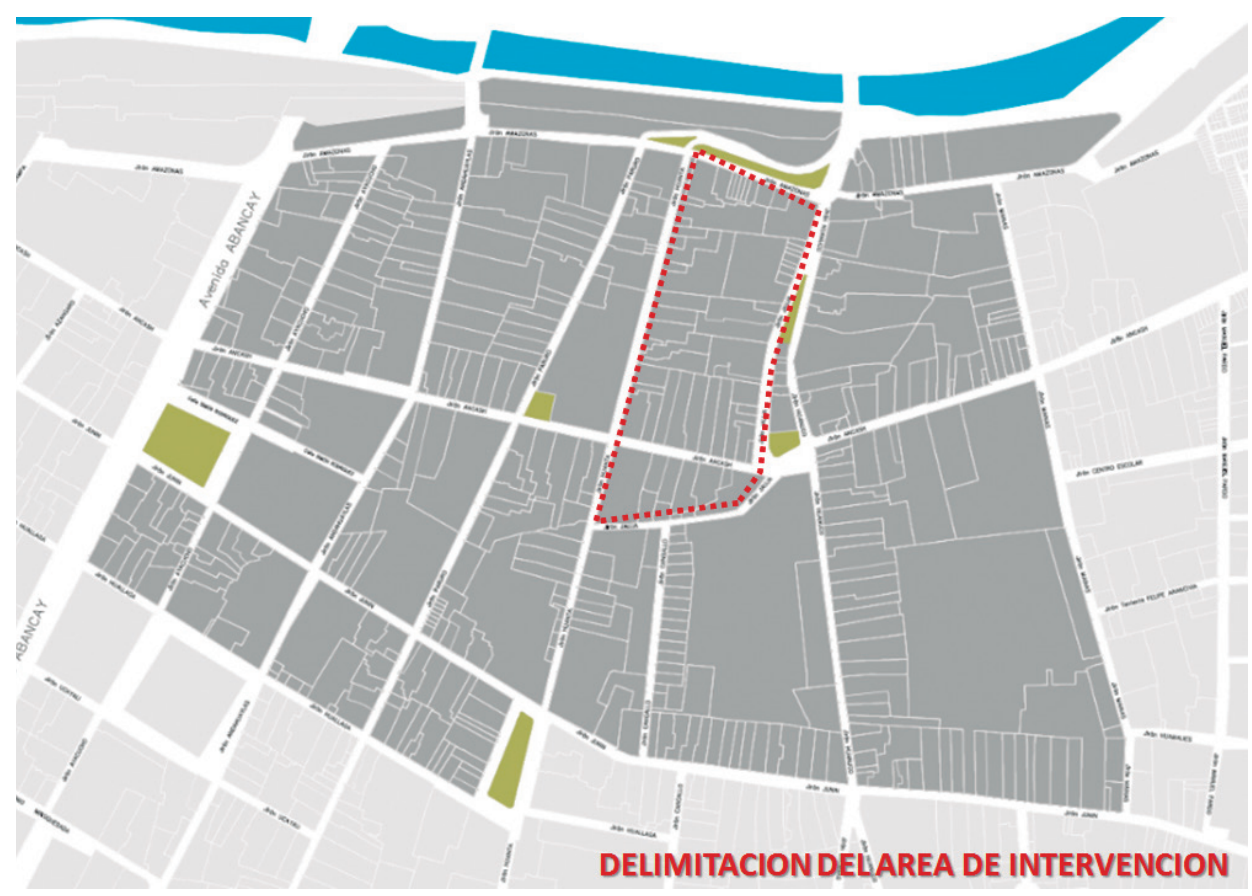

Humanidad y presenta tres inmuebles con categoría de monumento, cinco de valor monumental y tres de entorno. Entre ambas manzanas, existe un total de 65 inmuebles que tienen la zonificación de Zona de Tratamiento Especial 2 (ZTE-2); esta fue establecida mediante la Ordenanza 893-MML (2005) bajo el siguiente sustento:

....el reajuste integral de Zonificación del Cercado de Lima, en la Zona del Centro Histórico de Lima establece solo tres (3) grandes zonas especiales de usos del suelo, en las cuales se reconocen perfiles urbanos y viales formados a través del tiempo, así como vocaciones de uso diferenciadas según su potencialidad funcional, espacial y compromiso monumental y, en donde, las actuaciones deben orientarse fundamentalmente a la plena recuperación de sus condiciones urbanas, constructivas y operativas. (p. 307298) (ver Figura 8)

En esta configuración de 65 inmuebles, el $75 \%$ tiene uso de vivienda y el $25 \%$ tiene usos incompatibles -mixtos entre comercio, depósito y vivienda-, lo que concentra la mayor cantidad de densidad poblacional en los inmuebles más deteriorados con viviendas del tipo quinta. En el caso de la manzana 6007 , el $26 \%$ de inmuebles presentan alta densidad y el $74 \%$ baja densidad, lo que resulta en una densidad neta de 300 a 1000 hab./ha; por otro lado, en la manzana 6016 , el $27 \%$ presenta alta densidad y el $73 \%$ baja densidad, con una densidad neta de 0 a 300 hab./ha (ver Figura 9).

La Ordenanza 893-MML (2005) establece un área libre mínima de 30\% para edificaciones nuevas, a excepción del uso comercial. En este sentido, orientado al uso de vivienda, la manzana 6007 presenta un área libre de 33.67\%; sin embargo, al analizar el área libre de acuerdo a su uso de suelo encontramos que $9 \%$ es de usos incompatibles y solo $25 \%$ es adecuado para uso de vivienda, lo que presenta un déficit de $5 \%$. Por otro lado, la manzana 6016 tiene un área libre total de $28.93 \%$; solo $16 \%$ es de uso de vivienda y $12.93 \%$ es de usos incompatibles, lo que representa un déficit de 14\% (ver Figura 10).

Ninguna de las dos manzanas presenta áreas verdes en su interior; sin embargo, su entorno inmediato, alrededor de 10 manzanas a la redonda que conforma un área de $415,825.98 \mathrm{~m}^{2}$, presenta $6.48 \%$ de áreas verdes, secciones de parques, plazuelas o jardines interiores. Cabe mencionar que esta tipología de espacios interiores y morfolo- 


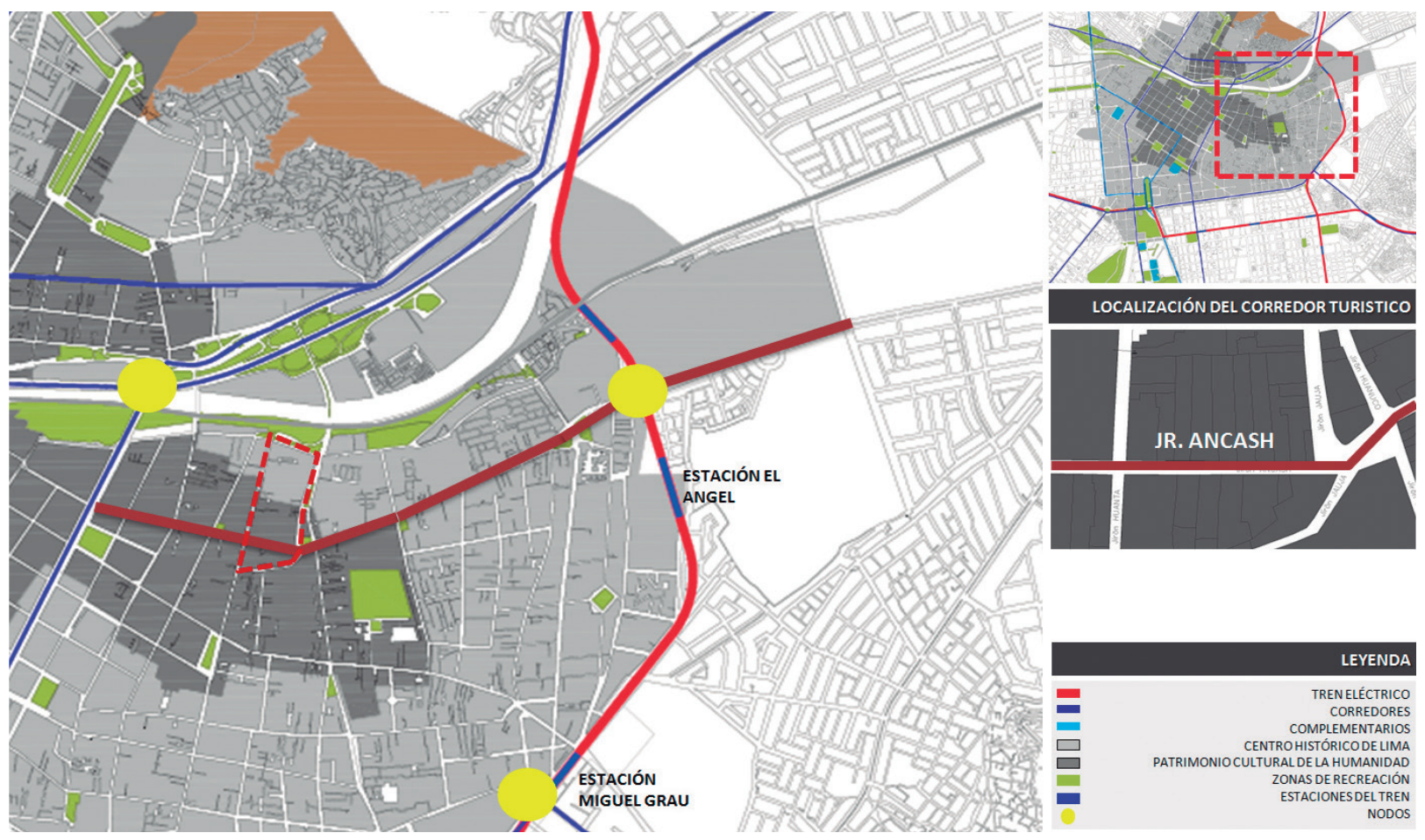

Figura 7. Accesibilidad vial

Fuente: Ordenanza 341-MML y Propuesta del Plan Concertado del Cercado de Lima - GDU-MML, 2014.

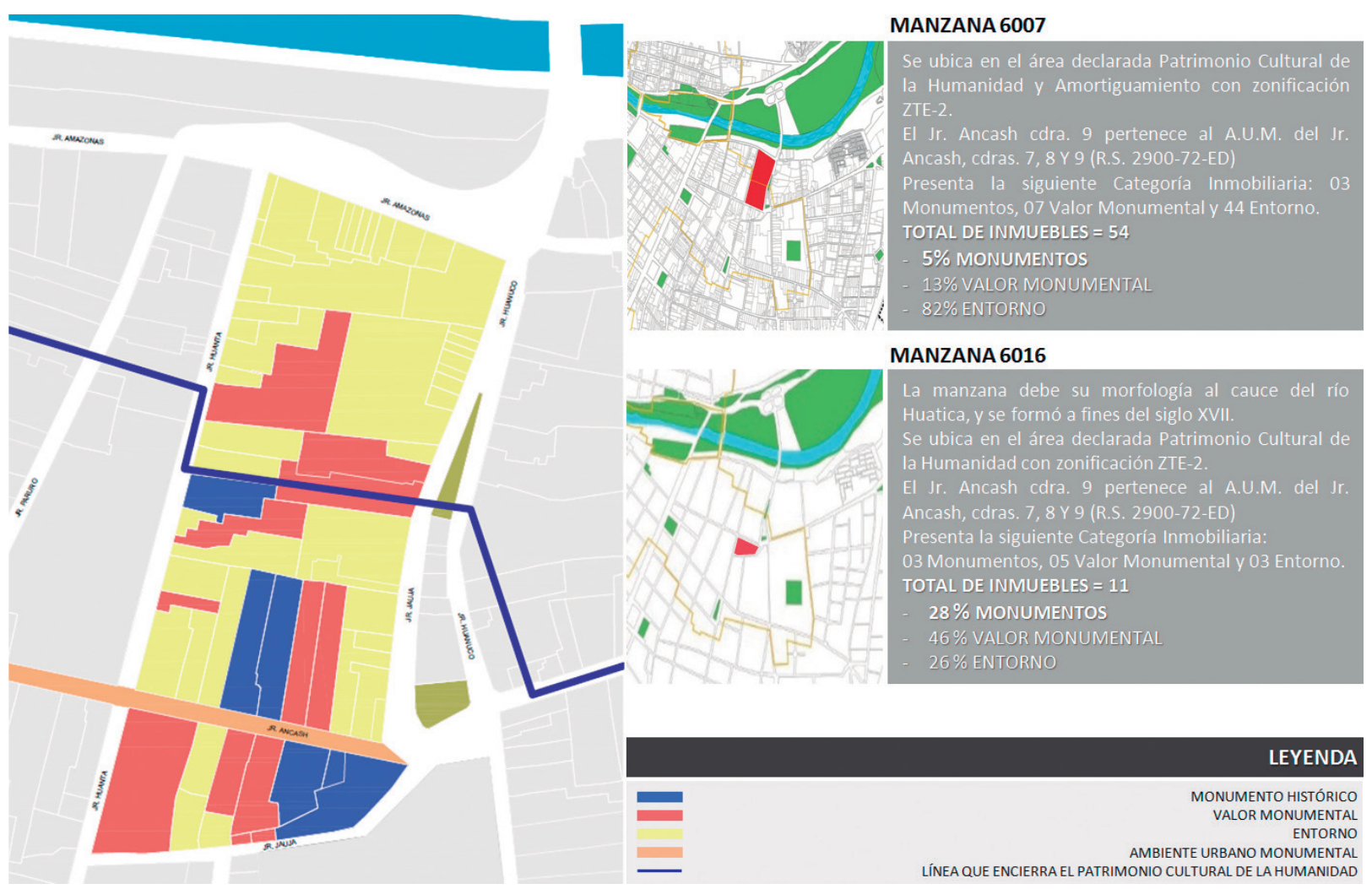

Figura 8. Mapeo de análisis de Monumentalidad

Fuente: Propuesta de lineamientos básicos orientadores (L.B.O.) técnicos para áreas de tratamiento con fines de Renovación Urbana, 2014. 
devenir Vol. 3, N5, ENERO- JUNIO 2016, PP. 67-89 - EstudIOS I ISSN 2312-7570

UNIVERSIDAD NACIONAL DE INGENIERÍ, LIMA
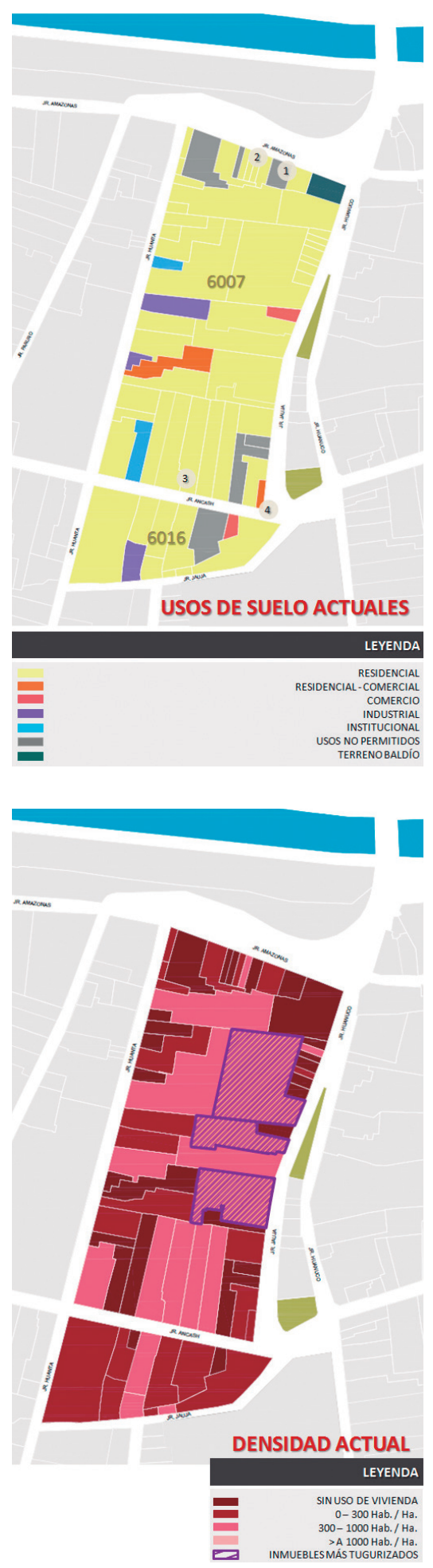

Figura 9. Mapeo de análisis de usos y densidad

Fuente: Propuesta de lineamientos básicos orientadores (L.B.O.) técnicos para áreas de tratamiento con fines de Renovación Urbana, 2014. gía es descrita como "....la existencia de una especie de ciudad interior constituida de un sistema en red de espacios (públicos y semipúblicos) en el interior de las manzanas o casas de patio de cierta magnitud [...] rasgo que se registra en Lima solo en aquellos espacios históricos..." (Ludeña, 2010, p. 38)

La vulnerabilidad estructural de los inmuebles existentes arrojó para la manzana 6007 que $92.74 \%$ de inmuebles tiene un alto grado de vulnerabilidad y $7.26 \%$ tiene un mediano grado de vulnerabilidad. La manzana 6016 tiene $81.66 \%$ de inmuebles con alto grado de vulnerabilidad y $18.34 \%$ con mediano grado de vulnerabilidad. Estas estimaciones de vulnerabilidad reflejan el mismo riesgo ante un escenario de sismo (ver Figura 11).

Esta situación crítica se refleja en el estado de conservación de los predios que conforman ambas manzanas, si se considera que $20 \%$ está declarado en estado de tugurización, y $11 \%$ ha sido declarado en estado de inhabitable y/o ruinoso durante los últimos 16 años; además de ello, $5 \%$ se encuentra en proceso de ser declarado estado de tugurización bajo la normativa vigente, Ley 29415 (2009). Si se considera que alrededor de $74 \%$ del total de predios cuentan con baja densidad, la mayor cantidad de población se concentra en estos inmuebles en constante degradación.

\section{Normativa vigente y sus limitaciones para el proceso de Renovación Ur- bana en el Centro Histórico de Lima}

Desde que se dieron las primeras intervenciones de renovación urbana entendidas como grandes demoliciones dirigidas, así como la idea de potenciadores de la economía urbana o de un gran proyecto catalizador, se ha llegado hasta la actual visión como proceso transformador de acciones, y proyectos donde el interés social y colectivo es lo prioritario. El Estado peruano propone la Normativa de Renovación Urbana; el Reglamento de la Ley de Promoción a la inversión privada en acciones de renovación urbana, en el artículo 2, define lo siguiente: “La Renovación Urbana es un proceso permanente y coordinado de acciones preventivas y correctivas del deterioro físico y socioeconómico de las áreas urbanas. Tales acciones se inscriben dentro del marco general de los Planes de Desarrollo Urbano." (1995)

Este proceso multidisciplinario e integral debería considerar una estructura de desarrollo que sustente su permanencia en el tiempo y, a la vez, sea retroalimentada para su reajuste cuando cada etapa concluya. Lamentablemente, los gobiernos locales no tuvieron, durante la aplicación de este proceso, una mirada de recuperación urbanística, económica y social a mediano y largo plazo; esto hizo que con esta política aumente la constante degradación y deterioro del Centro Histórico de Lima, donde el sector de Barrios Altos es uno de los más afectados.

A continuación se lista el marco normativo técnico-legal promulgado por el gobierno central y provincial (local), para acciones de renovación urbana:

\subsubsection{Decreto Legislativo 696, Ley de promoción a la inversión privada en} acciones de Renovación Urbana.

\subsubsection{Decreto Supremo 011-MTC, Reglamento de la Ley de Promoción a la inversión privada en acciones de Renovación Urbana.}

El gobierno central aborda el problema de recuperación de zonas urbanas deterioradas, al establecer un proceso de renovación urbana sujeto a áreas de intervención a nivel de predios, un conjunto de predios (microzona de tratamiento) o un área integral espacialmente continua (zona de tratamiento), delimitados por algunas características comunes y grado de deterioro. Dispone la formulación de programas de renovación urbana, a cargo de las municipalidades provinciales, a través de instrumentos que técnicamente establezcan áreas de tratamiento de intervención (microzona o zona) y Lineamientos 
Básicos Orientadores (L.B.O.) técnicamente viables. En la práctica aún no se delimitan áreas de tratamiento para renovación urbana ni L.B.O. que establezcan parámetros urbanísticos y edificatorios técnicos para la recuperación del Centro Histórico de Lima. El Programa Municipal para la Recuperación del Centro Histórico de Lima (PROLIMA) y la Subgerencia de Renovación Urbana (SRU) de la Gerencia de Desarrollo Urbano de la Municipalidad Metropolitana de Lima son los encargados de establecer acciones para concretar estas herramientas técnicas; estas tienen el propósito de incentivar a inversiones privadas o mixtas (público-privadas) a desarrollar proyectos de renovación urbana, especialmente en las zonas más degradadas del Centro Histórico de Lima.

\subsubsection{Ley 29415, Ley de saneamiento físico legal de predios tugurizados} con fines de renovación urbana.

30.10.2010 Decreto Supremo 011-2010-VIVIENDA “Reglamento de la Ley de saneamiento físico legal de predios tugurizados con fines de renovación urbana"

Establece un procedimiento progresivo, a través de cinco etapas con objetivos definidos, para cumplir con el saneamiento físico legal de predios en condiciones precarias e inhabitables, lo que genera una intervención de renovación urbana solo a nivel de microzona de tratamiento, sin considerar áreas integrales (zona de tratamiento) para intervención. En la práctica factores políticos, legales, sociales, económicos y técnicos opacaron el cumplimiento de las etapas para que algunos predios -de manera aislada- puedan beneficiarse de un proceso con fines de renovación urbana. A la fecha, en Lima y a nivel nacional, no existe una aproximación técnica (lineamientos de gestión, y parámetros urbanísticos y edificatorios) que ayude a concretar procesos de renovación urbana de gran impacto en centros históricos, y que mejoren la configuración urbana, dentro de un contexto monumental, y la calidad de vida de su población.

\subsubsection{Ordenanza 1643-MML, Programa metropolitano de vivienda popular} de la Municipalidad Metropolitana de Lima.

Este programa, a cargo de Empresa Municipal Inmobiliaria de Lima (EMILIMA), tiene como objetivo mejorar las condiciones habitacionales; promueve una adecuada densificación poblacional a través de la generación de oferta de viviendas para sectores populares. En la práctica no tuvo mayor integración con los procesos de renovación urbana en el Centro Histórico de Lima.

\section{Normativa del Centro Histórico de Lima}

La Regulación del Centro Histórico de Lima se caracteriza por la aprobación de propuestas técnicas que recorren de una visión general a un detalle específico -considerando el impacto del Plan Maestro Centro de Lima- y un devenir al origen. Así, se convierte al Centro Histórico de Lima en un laboratorio de ensayo que no responde a un trabajo multidisciplinario, que prioriza aspectos técnico-legales y socioeconómicos con una mirada integral a largo plazo; por el contrario, se responde a intereses políticos, que truncan o desechan estudios multidisciplinarios o propuestas técnicas con una mirada integral de ciudad, que podrían contribuir a una progresiva recuperación del Centro Histórico de Lima, que continúa en constante deterioro físico, social y económico.

A continuación se lista el marco normativo técnico-legal promulgado por la Municipalidad Metropolitana de Lima (MML), en tanto organismo regulador:

\subsubsection{Ordenanza 062-MML, Reglamento de Administración del Centro His- tórico de Lima.}

Se ocupa de orientar las intervenciones urbanas en el Centro Histórico de Lima, delimitando tres zonas que a su vez se dividen en 12 microzonas; sigue criterios de jerarquización, densidad, carácter monumental, homogeneidad de entorno y capacidad de recuperación.

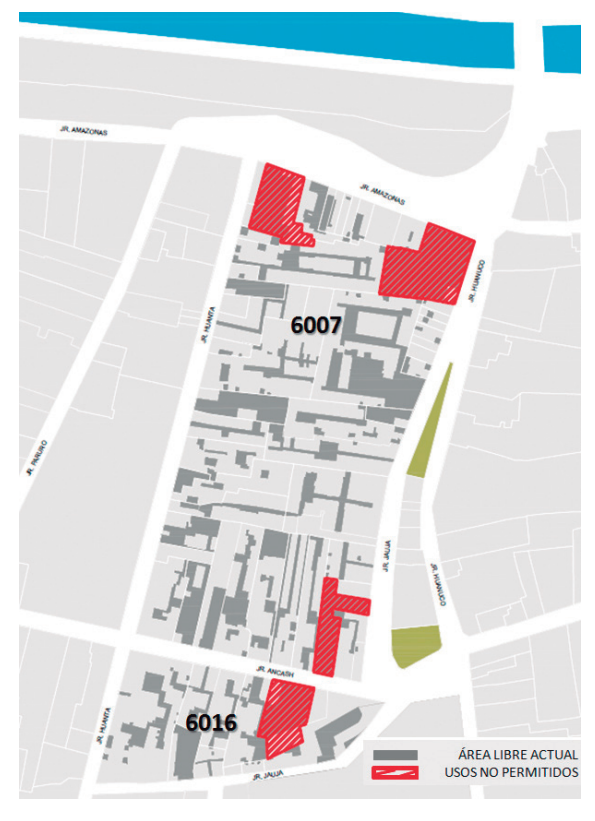

Figura 10. Mapeo de análisis de área libre

Fuente: Propuesta de lineamientos básicos orientadores (L.B.O.) técnicos para áreas de tratamiento con fines de Renovación Urbana, 2014. 

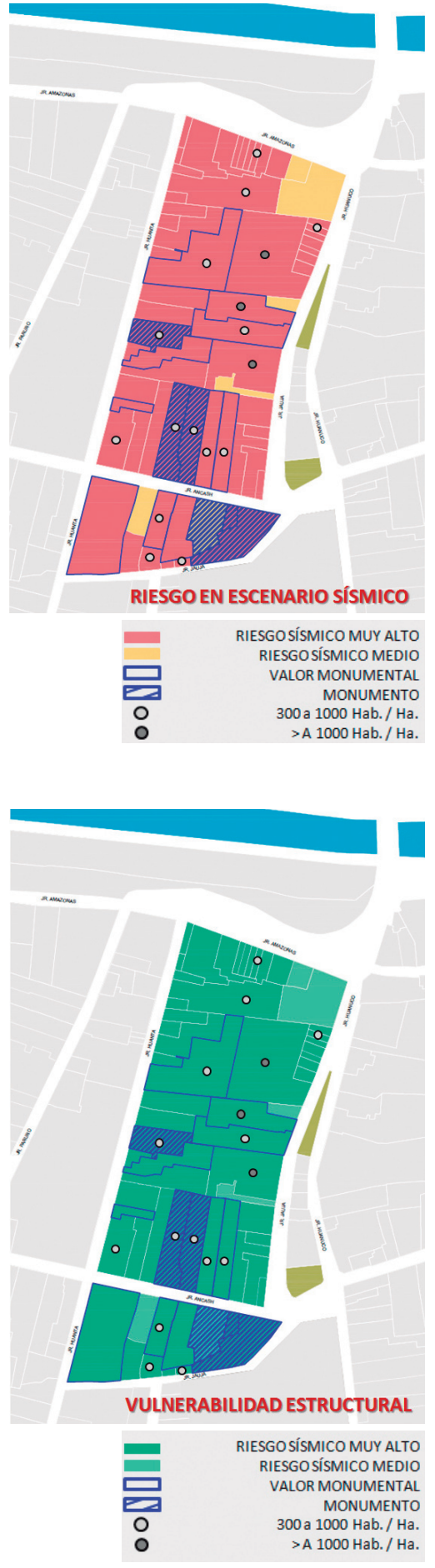

Figura 11. Mapeo de análisis de vulnerabilidad estructural

Fuente: Consultoría de elaboración de análisis, diagnóstico y propuesta legal, técnica y financiera con fines de renovación urbana de una zona de Barrios Altos, 2014.
Regula mediante parámetros administrativos y técnicos la diferenciación de los grados de intangibilidad de cada microzona; esto propicia el realce de sus características monumentales, y mantiene y recupera su volumetría y entorno inmediato al suprimir todo aquello que atente contra la armonía del contexto. Busca incorporar las nuevas edificaciones en armonía con el carácter del entorno, y recupera así los valores monumentales y culturales de cada zona. Se precisa que varios de los parámetros técnicos (urbanísticos y edificatorios) siguen vigentes, los cuales son considerados además en la Ordenanza 893-MML (ver Figura 12).

\subsubsection{Ordenanza 201-MML, Plan Maestro Centro de Lima.}

El capítulo III se ocupa del Centro Histórico de Lima como un área de tratamiento de carácter integral y complementa las disposiciones de la Ordenanza 062-MML. Identifica 22 zonas de tratamiento, para intervención de acuerdo a su naturaleza y características, así como los Corredores Turísticos Monumentales, que tienen por objetivo la recuperación de monumentos, calles y espacios públicos con declaración de Ambiente Urbano Monumental (AUM) para su uso turístico y cultural. Esto tiene la finalidad de repotenciar su sistema vial y afianzar al Centro Histórico de Lima como destino cultural del área metropolitana (ver Figura 13).

El capítulo IV se ocupa de la renovación urbana, y establece el rol activo de la Municipalidad Metropolitana de Lima mediante objetivos y acciones que den cumplimiento a lo dispuesto por el Decreto Legislativo 696 y su reglamento. A fin de concretar un proceso de renovación urbana que considere a cada área o zona de tratamiento previamente identificada, se debían desarrollar acciones de destugurización de viviendas y prevención de desastres, puesta en valor del patrimonio inmobiliario y del espacio público, consolidación del uso y del rol metropolitano, reconversión del uso del suelo y tratamiento eco-paisajístico.

Con este fin, para el sector de Barrios Altos, se identificaron siete zonas de tratamiento con L.B.O. bastante generales, desarrollados mediante el estudio Renovación urbana en Barrios Altos MML-IMP. Se planteó la elaboración del Reglamento Especial de Renovación Urbana de Barrios Altos a cargo del Instituto Metropolitano de Planificación (IMP); sin embargo, a la fecha esta importante iniciativa no se ha ejecutado. El artículo 64, por ejemplo, nos muestra una concepción integral de recuperación monumental y espacial:

Los proyectos de renovación urbana con fines de destugurización de viviendas, en los barrios altos se ejecutaran preferentemente abarcando una o más manzanas, con la apertura de frentes internos mediante calles, pasajes, parques y estacionamientos, alrededor de los cuales se construirán viviendas en altura, conservando en las fachadas externas de las manzanas el perfil urbano del área monumental. (1999)

Esta ordenanza consolidó una importante propuesta técnica, y desarrolló un trabajo más detallado, orientado a recuperar el carácter monumental de Barrios Altos, que debió ser retomado en la normativa precedente.

\subsubsection{Ordenanza 893-MML, Reajuste Integral de la Zonificación de los Usos de Suelo del Cercado de Lima.}

Establece la zonificación de los usos de suelo y el índice de usos para la ubicación de actividades urbanas en el Centro Histórico de Lima. Esta zonificación dispuso tres zonas de tratamiento, en las cuales se reconocen sus vocaciones de uso según su potencialidad funcional y compromiso monumental. Definió parámetros urbanísticos y edificatorios para cada zona de tratamiento, con una visión muy conservadora y general sobre las características que mantiene cada microzona, sin un mecanismo técnico que incentive procesos de renovación urbana con inversión privada o mixta (pública-privada). 

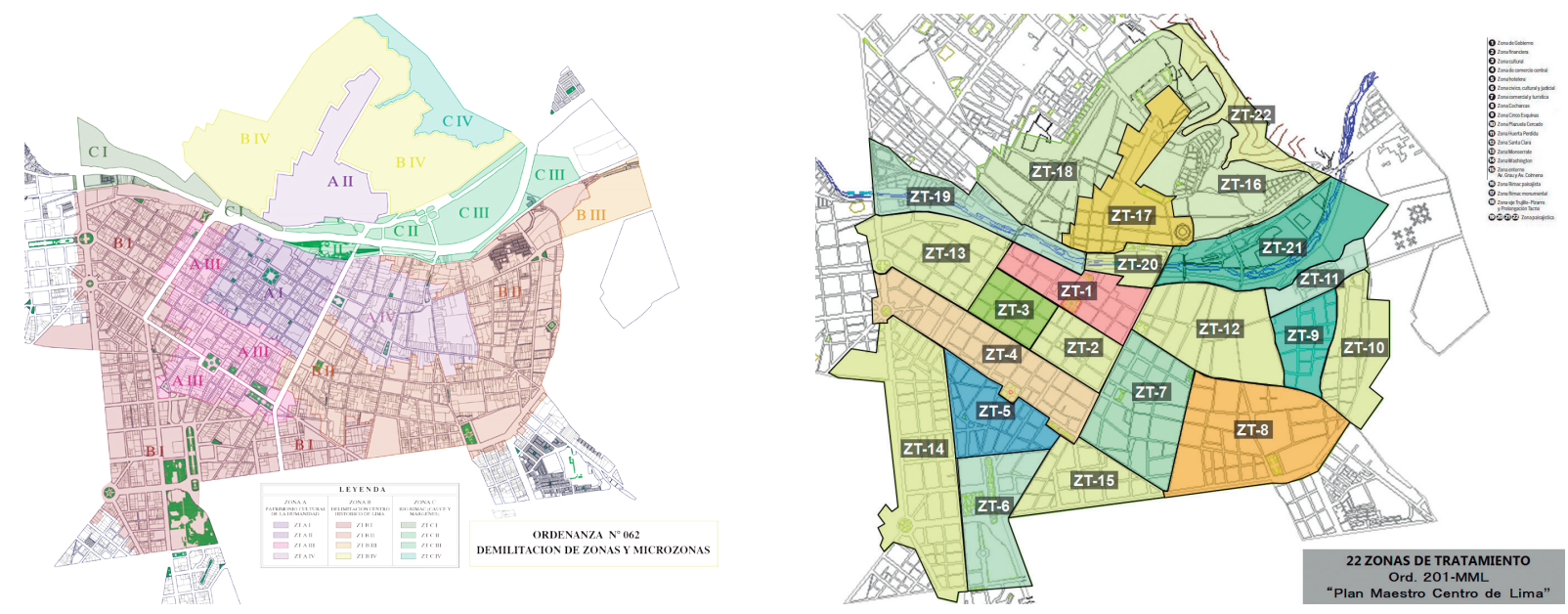

Además, declara de interés "el centro Histórico de Lima como área preferencial para la inversión pública y privada en materia de vivienda", y dispone la conformación de una Comisión de Alturas de Edificaciones del Centro Histórico de Lima para que elabore un instrumento de gestión técnico de vital importancia como lo es el plano de alturas, aún sin concretarse.

11.04.2006 Ordenanza 931-MML, Que amplía plazo establecido en la Ordenanza 893MML.

\section{Casuística latinoamericana para afrontar procesos de renovación urbana en centros históricos}

La selección de los centros históricos como objetos de estudio parte de dos criterios: en primer lugar, que cuenten con la categoría de Patrimonio Cultural de la Humanidad; en segundo lugar, que sean experiencias exitosas latinoamericanas en renovación urbana, según criterios de semejanza y similitud basados en aspectos históricos, escala urbana y de problemática social, validados con especialistas para mayor confiabilidad.

Los casos de intervención seleccionados fueron los siguientes: Centro Histórico de Quito (1978) ', de Cuba (1982), de México (1987) y de Cartagena de Indias (1984); ser seleccionados implicó la realización de un mapeo por usos de suelos, tipo de monumentos y nivel de intervención. De esta forma, se pudo construir una matriz de análisis, y obtener conclusiones genéricas y por variable de análisis de la intervención (ver Figuras 14, 15, 16 y 17).

Finalmente, el tercer filtro de análisis sirvió para elegir las variables de análisis basadas en criterios de diseño arquitectónico establecidos en el Reglamento Nacional de Edificaciones (RNE), y Parámetros Urbanos y Edificatorios (PUE); la finalidad era buscar la reconfiguración morfológica de las manzanas 6007 y 6016, mejorar las condiciones de habitabilidad del poblador y recuperar sus valores patrimoniales.

Los resultados finales pueden observarse en la Tabla 1.

Las estrategias de intervención factibles según la realidad urbana de Barrios Altos son las siguientes: integración al contexto urbano-monumental, heterogeneidad de usos de suelo, conservación morfológica de la manzana, priorización del transporte público, gestión de riesgos y, finalmente, fortalecimiento de las viviendas, esto último como acción prioritaria.
Figura 12. Plano aprobado por Ordenanza 062-MML

Fuente: Anexo de Ordenanza 062MML, 1994.

Figura 13. Plano aprobado por Ordenanza 201-MML

Fuente: Anexo de Ordenanza 201MML, 1999.

\footnotetext{
1. Año que fue designado Patrimonio Cultural de la Humanidad.
} 
devenir Vol. 3, N5, ENERO- JUNIO 2016, PP. 67-89 - EstudIOS I ISSN 2312-7570

UNIVERSIDAD NACIONAL DE INGENIERÍA, LIMA

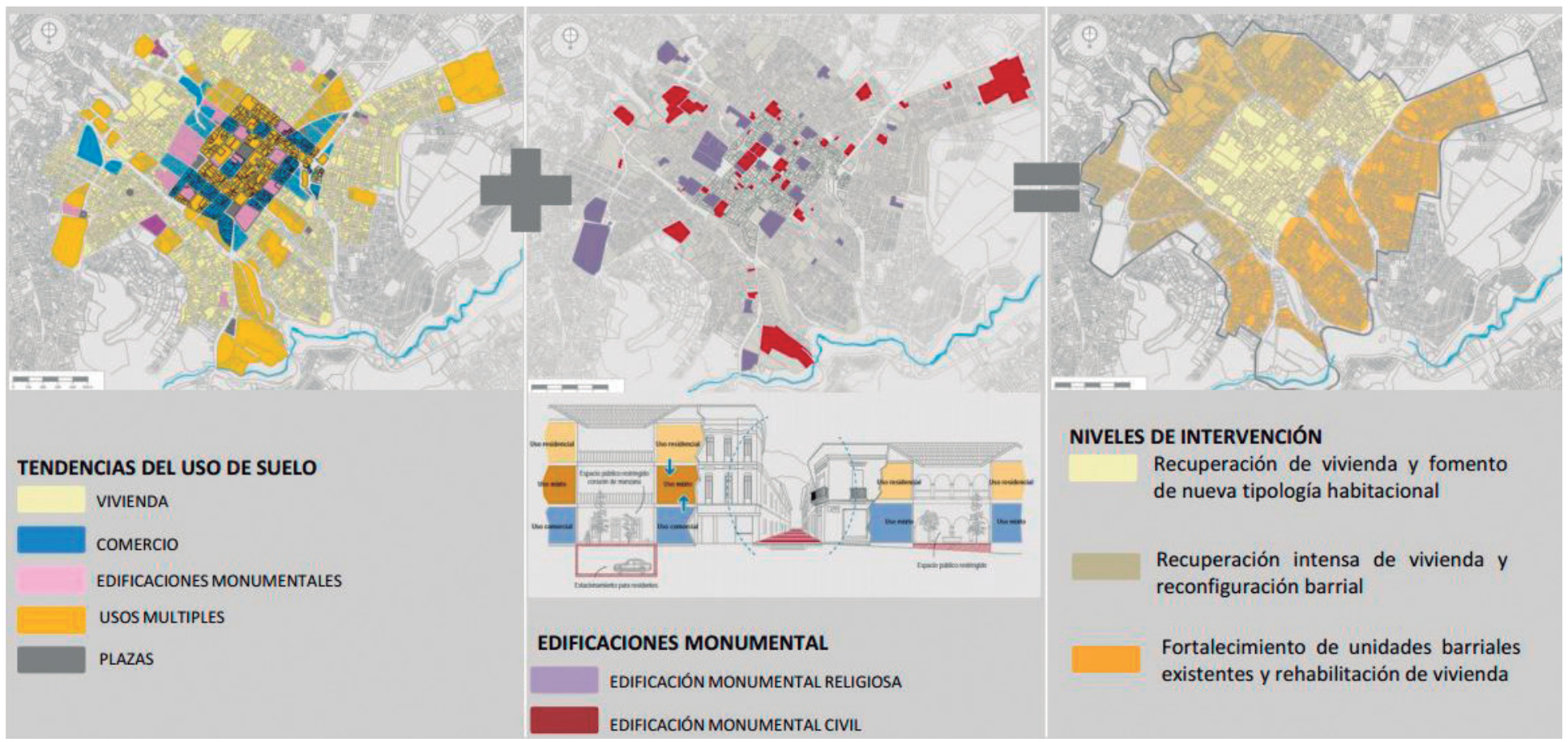

Figura 14. Mapeo por usos de suelos, monumentos y tipo de intervención de Quito

Fuente: Plan Especial del Centro Histórico de la ciudad de Quito, 2013.
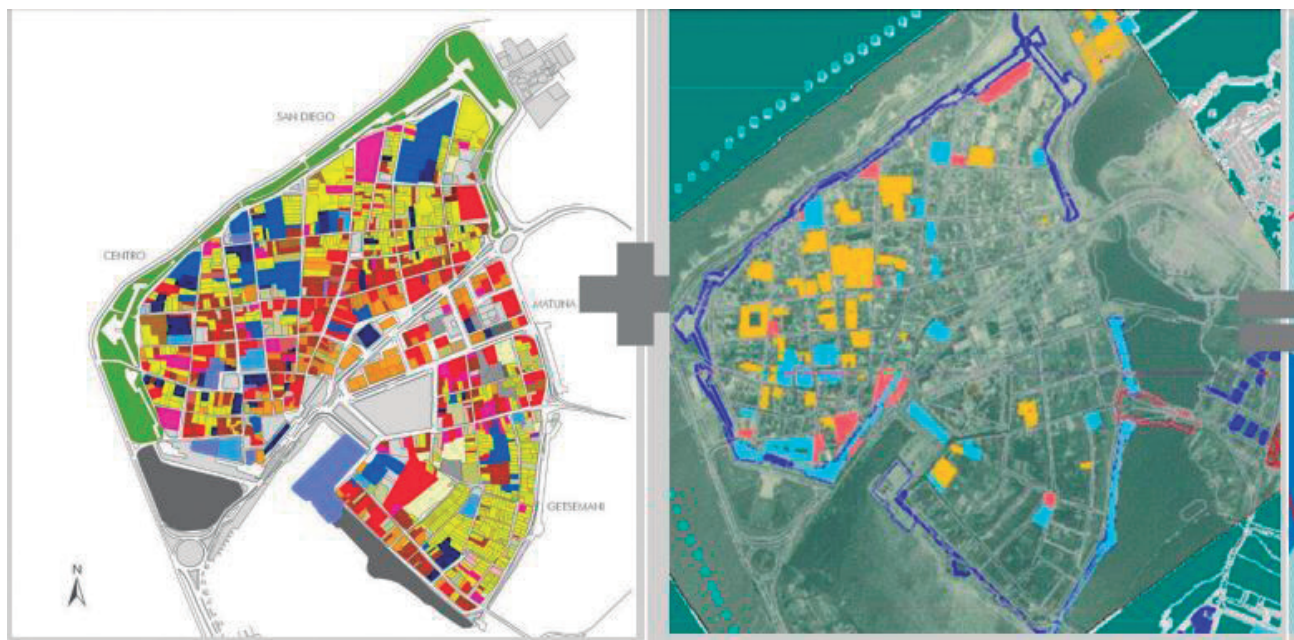

USO DE SUELO

VIVIENDA
COMERCIO
EDUCACIÓN
TURISTICO_HOTELERO
AREA VERDE

\section{MONUMENTOS}

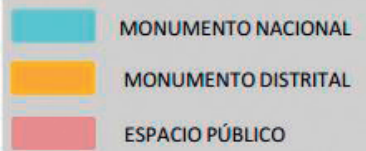

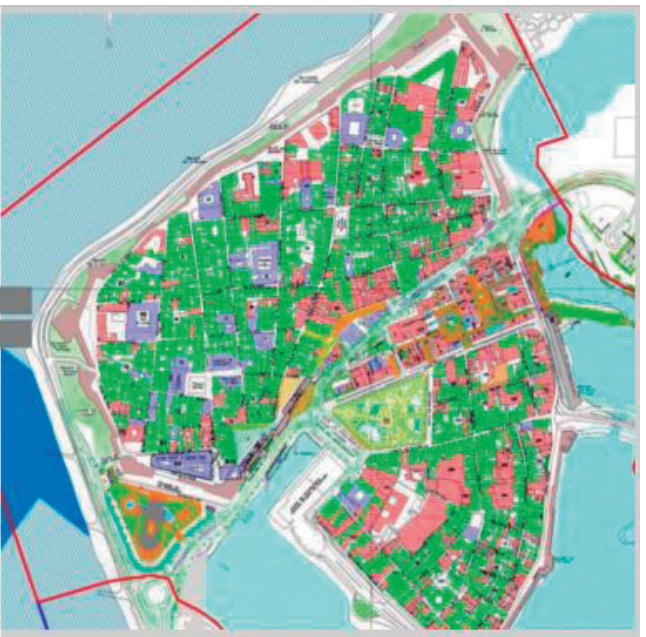

NIVELES DE INTERVENCIÓN

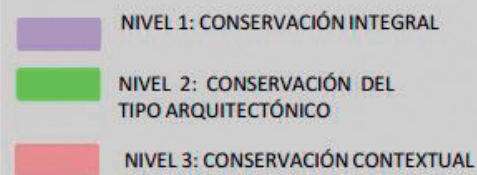

Figura 15. Mapeo por usos de suelos, monumentos y tipo de intervención de La Habana Fuente: Plan Especial de desarrollo integral (2010-2015) La Habana-Cuba, 2014. 


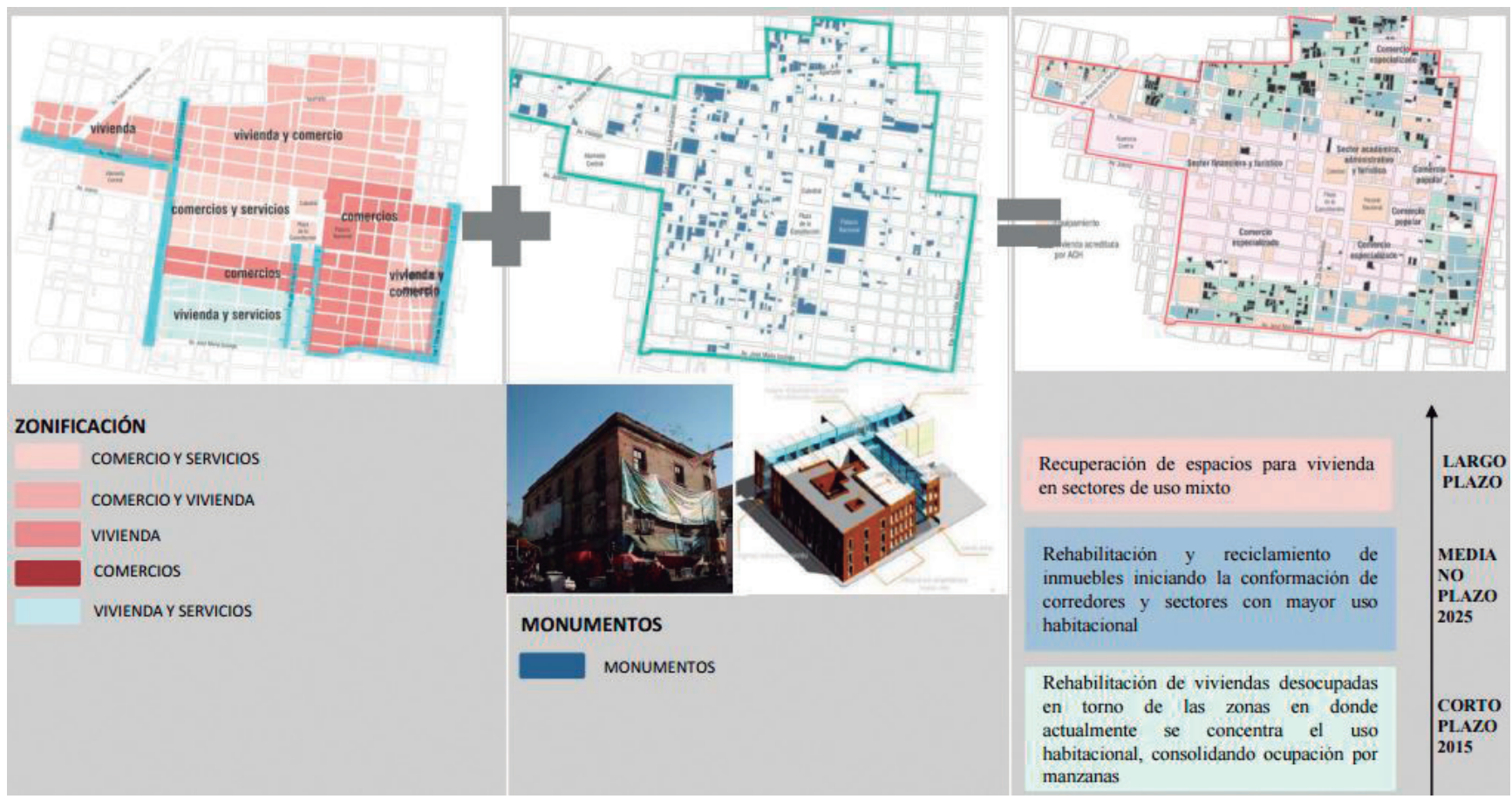

Figura 16. Mapeo por usos de suelos, monumentos y tipo de intervención de México

Fuente: Plan Integral de manejo del Centro Histórico de la ciudad de México (2011-2016), 2014.

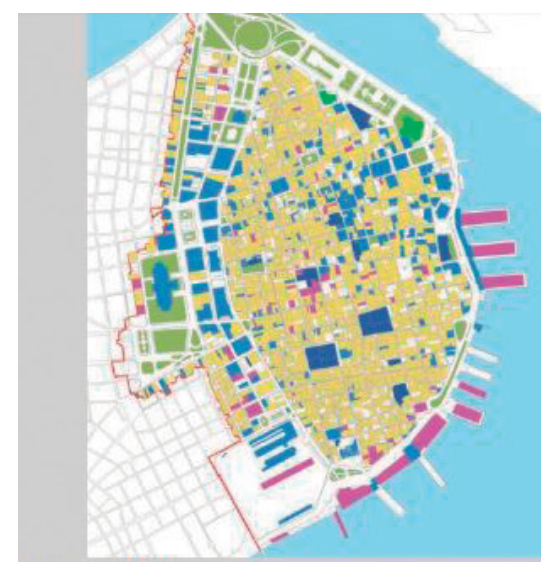

USO DE SUELO

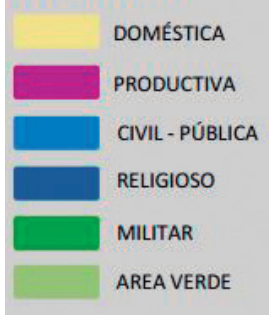

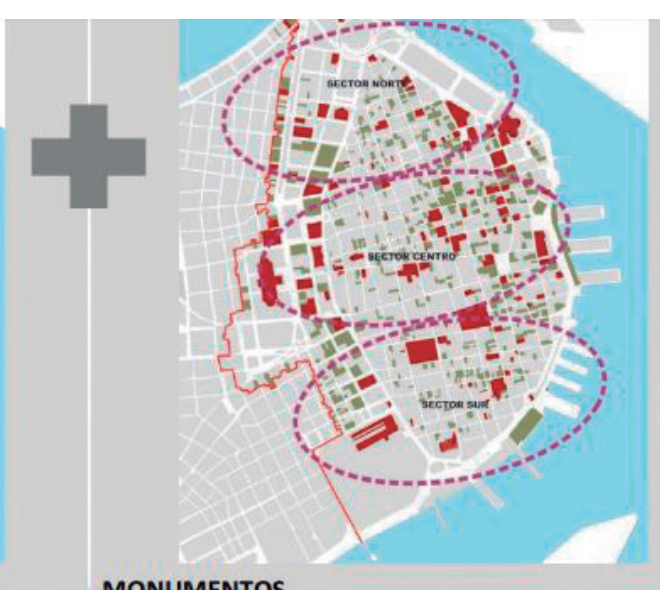

MONUMENTOS

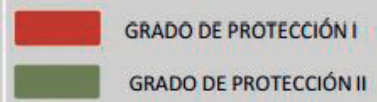

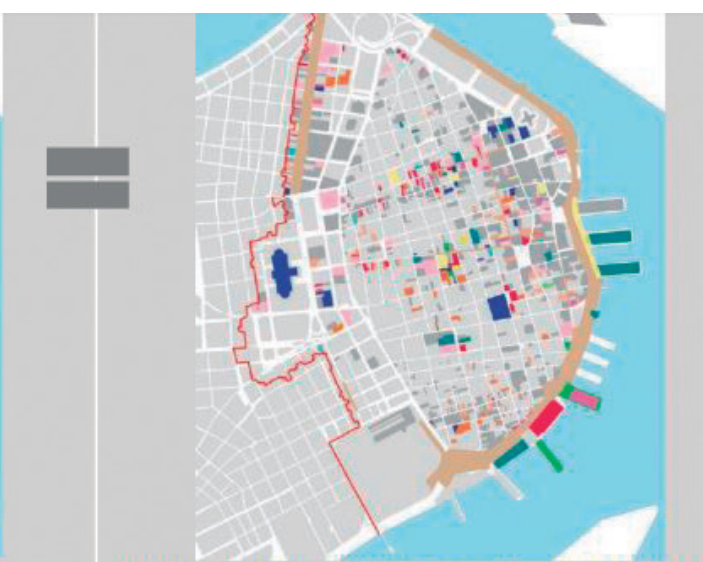

INTERVENCIONES PROPUESTAS (USOS Y CANTIDAD)

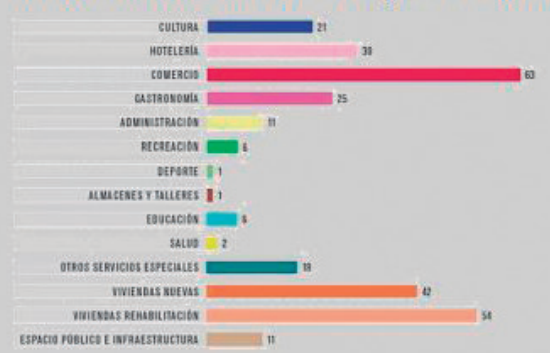

Figura 17. Mapeo por usos de suelos, monumentos y tipo de intervención de Cartagena de Indias Fuente: Plan Especial de manejo y protección del Centro Histórico de Cartagena de Indias, 2014. 
Es importante mencionar que, además, se halló en los centros históricos seleccionados la existencia de diferentes niveles de gestión: nacional e internacional. Esto convirtió en una arista de vital importancia la gestión para canalizar fondos de cooperación y financiar las intervenciones urbanas. La importancia de la cooperación y asistencia técnica internacional en la parte inicial de los proyectos de intervención indica que antes de la firma de los convenios ya existía la presencia de un equipo preocupado por este aporte; en estos casos, estaban liderados por la gestión edil o el Estado.

\section{Una reflexión sobre los lineamientos básicos orientadores (L.B.O.), y pa- rámetros urbanísticos y edificatorios propuestos para la reconfiguración morfológica de las manzanas 6007 y 6017}

Una zona tan neurálgica y sensible como es Barrios Altos se destaca por el acelerado debilitamiento del carácter residencial, consecuencia del abandono de sus habitantes; por el continuo estado de precariedad de sus viviendas; por la descontrolada expansión del comercio informal con usos incompatibles (deposito-vivienda-comercio); y por la falta de planificación y fiscalización por parte de las autoridades. Estos fenómenos han ocasionado que se pierdan las características y costumbres propias de este barrio histórico de extenso valor monumental, y han dado paso a la proliferación de empresarios y trabajadores -población flotante- que, ante la falta de conciencia por la recuperación de nuestro patrimonio arquitectónico, poco ayudan a evitar el proceso de degradación constante.

Esta problemática es ampliamente conocida por las autoridades y la sociedad civil; sin embargo, somos testigos - desde dentro o fuera- del actuar de las autoridades, que se destacan por la falta de iniciativa o de respuesta inmediata ante un problema que tendrá consecuencias a futuro, así como del poco trabajo concertado como equipo.

Motivados por contribuir a modificar esta situación generalizada en el Centro Histórico de Lima, la cual afecta drásticamente a la zona de Barrios Altos e incluye al sector donde se emplazan las dos manzanas que son materia del análisis, el Proyecto de Recuperación del Centro Histórico de Lima - PE-LL7-BID (2013), así como EMILIMA y su Programa de Vivienda Popular, convocan a la cohesión de los diversos actores - dependientes directos y Oficinas Públicas Desconcentradas (OPD)- de la Municipalidad Metropolitana de Lima para el desarrollo de un plan integral de renovación urbana de las manzanas con códigos catastrales 6007 y 6016. Mediante la participación de PROLIMA, la Subgerencia de Renovación Urbana (SRU) de la Gerencia de Desarrollo Urbano, la Gerencia de Participación Vecinal y la Gerencia de Defensa Civil (que careció de constancia en su participación), se propuso una visión y objetivos concertados para la renovación urbana, los cuales conciliaron la normativa citada arriba de las décadas de 1990 y 2000 con los documentos de trabajo que se desarrollaron durante el año 2014. Entre ellos se encuentra el Plan Concertado del Cercado de Lima 2014-2025, hecho por la Gerencia de Desarrollo Urbano, y el Plan Maestro del Centro Histórico de Lima al 2025, desarrollado por PROLIMA.

El equipo interdisciplinario trabajó coordinadamente en las diversas áreas, y encargó a la División Técnica de la Subgerencia de Renovación Urbana (SRU) de la Gerencia de Desarrollo Urbano la elaboración de los Lineamientos Básicos Orientadores (L.B.O.) técnicos, en coordinación con PROLIMA.

El objetivo, a mediano y largo plazo, para el Centro Histórico de Lima -y en especial para la zona de Barrios Altos- planteaba lograr un "....centro vivo, habitable, seguro, sostenible e inclusivo, que mediante un proceso multidisciplinario recupere su valor histórico y patrimonial excepcional, manteniendo su identidad y tradiciones inserto en la dinámica de la metrópoli como lugar de encuentro de culturas." (SRU-GDU/PROLIMA, 2014, p. 4)

Fue interesante proyectar una visión concertada que enfoque un proceso multidisciplinario; sin embargo, en la práctica fue difícil intentar que todos los actores coordi- 
nen, cooperen y trabajen al mismo ritmo, dejando de lado sus intereses y carga laboral para conformar un solo equipo de trabajo concertado. La definición de 'equipo interdisciplinario' señala que "....la integración armónica de un conjunto de individuos que interactúan en forma duradera, para el logro de uno o varios objetivos comunes, por medio de una autoridad técnica y administrativa que, aunque centralizada, considera la delegación de funciones." (Menenghello, 1972, p. 82).

Se comprobó ciertamente que las políticas laborales de diversas dependencias fluctúan entre el recelo por compartir información y una orientación a lograr objetivos aislados que contribuyan a su propio bienestar, a pesar de su condición de servidores públicos.

Con la formulación de los Lineamientos Básicos Orientadores (L.B.O.) de carácter técnico-socioeconómico, se afinaron asperezas en el equipo. Se buscó que su contenido esté respaldado considerando el artículo 14 del D.S. 011-MTC, que señala

....la información socio-económica y técnico-normativa del área de tratamiento. Igualmente, los objetivos generales para la intervención; el tipo de acciones a aplicarse con relación con otras áreas, sectores o distritos y el conjunto urbano total, los usos de suelo; las densidades poblacionales y otras referencias para orientar la formulación de proyectos de renovación urbana. (1995)

Si bien se cumplió con el análisis y procesamiento de gran cantidad de información socioeconómica y técnica, parte importante de este proceso integral, no se pudo desarrollar, ni siquiera considerar, el tipo de acciones pertinentes para la aplicación de los lineamientos, y parámetros urbanísticos y edificatorios planteados. Es decir, no se logró obtener un instrumento de gestión que coordine la participación de los diversos actores, y oriente el proceder para la correcta participación e intervención activa sector público y privado (ver Figura 18).

Si se consideran las lecciones aprendidas al evaluar la normativa preexistente, destacan los lineamientos técnicos para las zonas o áreas de tratamiento establecidas. La presente propuesta tuvo la virtud de afinar los lineamientos técnicos, y materializarlos a nivel de parámetros urbanísticos y edificatorios que otorgan seguridad jurídica, e incentivan la inversión privada o mixta en una zona de alta degradación como Barrios Altos. Se optó por analizar y reflexionar sobre casuística internacional, que marca una referencia tangible de casos exitosos ejecutados en realidades similares a la nuestra, y por considerar los planes en desarrollo para el Centro Histórico de Lima en el año 2014, lo que representó una iniciativa por conciliar la mayor cantidad de información técnica de calidad disponible, y dejó de lado los intereses políticos e individuales, así como la burocracia administrativa.

El plantear parámetros, urbanísticos y edificatorios, para las dos manzanas con códigos catastrales 6016 y 6007, considerándolas como una sola unidad espacial y funcional a nivel de microzona de tratamiento, conllevó a poder resolver situaciones desfavorables. Por ejemplo, se logró cumplir con el número total de estacionamientos requeridos concentrándolos en la manzana 6007, de mayor extensión.

Si se analiza el caso de los estacionamientos, se consideró disminuir la alta presencia de espacios destinados a este fin en los primeros niveles de los inmuebles, que perjudican las dinámicas urbanas y la consolidación del correcto estado de conservación del Centro Histórico. De esta forma, se procura cubrir el déficit de espacios de estacionamientos para el área comercial del entorno inmediato mediante la modalidad de renta de 414 espacios de estacionamiento, lo que hace autosostenible la inversión inmobiliaria.

El ratio propuesto fue de un estacionamiento por cada diez viviendas con fines de renovación urbana ( $25 \%$ del total de viviendas), un estacionamiento cada seis para los programas fondo MIVIVIENDA S.A. u otros (75\% del total de viviendas), y un estacionamiento cada $100 \mathrm{~m}^{2}$ de área de comercio y oficinas. 
devenir Vol. 3, N5, ENERO- JUNIO 2016, PP. 67-89- EstudIOS I ISSN 2312-7570

UNIVERSIDAD NACIONAL DE INGENIERÍA, LIMA

Tabla 1. Matriz de análisis por Centro Histórico según variables de intervención

México

Ecuador

Colombia

Cuba

Conclusiones Central

Altura -Para proyectos localizados dentro del Primer Contorn de hasta 5 NIVELES (PB más 4 niveles -6 NIVELES (PB más 5
- Respeta el inmueble de entorno, mediante

el estudio de las calles visuales.

- La altura de la edificación nueva no debe superar en dos pisos las alturas máximas

permitidas en los lotes frontal y colindantes. máximaectos de rehabilitación, la altura tratamiento. tratamiento.
- Se puede realizar el incremento de alturas, condicionando a que el nuevo proyecto debe ener: reutilización de aguas servidas, energ
alternativa y tecnologías amigables.

son de $14 \mathrm{mts}$. $+/-3$

El inmueble con una

altura +3 metros, tienen
que tener un ancho de vía que tener un ancho de $v$ mínima de 17 metros.
ming
-Se respeta las alturas predominantes y los inmuebles - Toda nueva edificacion que colinde con un inmuebl de grado de protección I (monumento), no excederá la altura de éste.

- En proyectos de hoteles, oficinas para la renta, instalaciones extra hoteleras, etc. cada nivel añadido sobre la altura mínima estará sujeto a convenio para adquirir e derecho de crecimiento, hasta cubrir la altura máxima incluidos los retranqueos.
La tendencia en los centros históricos es crecer entre 4 y 6 niveles, siempre en cuando se respete el contexto y se encuentre condicionado a implemen condiciones.
condiones en buents
El volumen posterior se encontrará a $3 \mathrm{~m}$. (por piso a construir) desde la línea de la fachada; pudiéndose a partir de la última planta sobrepasar un plano de $45^{\circ}$
Todo edificio con grado de protección III y IV (valor monumental) podrá crecer:

1 piso completo, si tiene un solo nivel construido.

2 pisos completos, si tiene dos o más niveles.

El volumen posterior será de 2.75 (similar medida a la al-

tura por piso; altura de piso de volumen posterior: 2.75 )
Se concluye que tres de los centros históricos analizados permiten el volumen posterior, el cual debe estar irado $2.75 \mathrm{~m}-5.00 \mathrm{~m}$ desd la línea de la fachada.

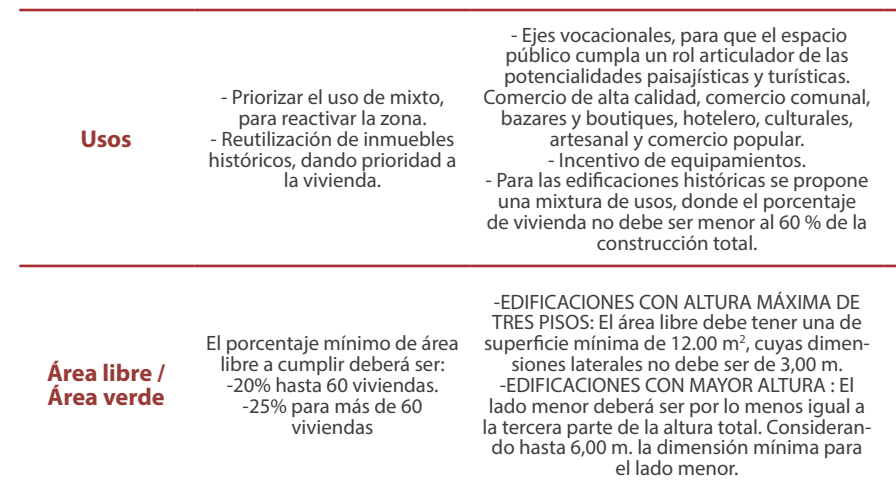

Se Permite la ocupación total de la planta baja para uso no residencial, para los demás niveles el uso permitido es residencial.

\section{-Se prioriza la mixtura de usos, siendo el uso residen-} cial el principal uso.

- Inserción de nuevos servicios comunitarios, espacios de recreación, comercial y cultural.

Las principales consideraciones que destacan son: y gastronómico.
La tendencia del uso de suelo en los centros históricos estudiados es incentivar el uso mixto: residencia y otros usos.
Se establece las áreas libres mediante los Coeficientes de Ocupación de Suelo (COS) en donde se considera lo siguiente: mino es 0,75 , donde deberá poseer el $25 \%$

La obra nueva deberán cumplir con las dimensioun lado no menor de $3 \mathrm{~m}$
Densidad

Poblacional /

Área de

El área máxima construida

vivienda por vivienda (sin incluir
Con una densidad actual promedio de 65.19 hab/ha en el centro histórico, se propone una densidad promedio a llegar de $168 \mathrm{hab} /$ ha, donde las áreas de vivienda aproximada oscilan entre los $38 \mathrm{~m}^{2}$ a $120 \mathrm{~m}^{2}$
No se indica el área mínima de vivienda. de área descubierta como mínimo

Si el COS es de 0,85 (edificaciones de $12 \mathrm{~m}$ de altura) su área descubierta es $15 \%$ como mínimo área descubierta es 20\% como mínimo
La tendencia de área libre de los centros históricos estudiados es de $20 \%$ a $25 \%$, asimismo se impulsa a respetar la tipología de vi históricos.
Se propone uniformizar las densidades de las zonas (200 hab/ha) estableciendo diversidad de tipologías de vivienda ( $20 \%$ de 1 dormitorio; $50 \%$ d en viviendas con área mínima de $25 \mathrm{~m}^{2}$ ( 1 dormitorio) 2. Para obra nueva y/o rehabilitación se establecen areas minimas de vivienda:

- Vivienda de 2 dormitorios: $60-75 \mathrm{~m}^{2}$

Vivienda de 3 dormitorios: $75-120 \mathrm{~m}^{2}$
1. Para edificaciones existentes se permite subdividi áreas mínimas de vivienda:
La tendencia del área como mínimo de $38 \mathrm{~m}^{2} \mathrm{y}$
como máximo de $120 \mathrm{~m}^{2}$ aproximada de vivienda es

\section{\begin{tabular}{cc}
\hline & El porcentaje de cajones de \\
estacionamiento deberá \\
ser mínimo de $30 \%$ para \\
Estaciona- \\
mientos & $\begin{array}{c}\text { vivienda de interés social, en } \\
\text { régimen condominio. En el } \\
\text { caso de la vivienda de interés } \\
\text { popular, será del } 60 \%\end{array}$
\end{tabular} \\ - Se implemento el programa sanitaria y pluvial. \\ Gestión de - Renovación de la infraes- \\ riesgos tructura eléctrica. Las redes colocados en el subterráneo. -Implementación de un programa de interno}

Se propone un sistema peatonal en el centro histórico, por lo cuál se plantean estacionamientos en los bordes para poder Para edificaciones de carácter residencial se determinará lo siguiente:

-Viviendas con un área igual a menor de $38 \mathrm{~m}^{2}$ deberá tener 1 por cada 6 viviendas. -Viviendas de áreas de más $38 \mathrm{~m}^{2}$ hasta 120 $\mathrm{m}^{2}$, deberá tener 1 por cada 3 viviendas tener 1 por 2 viviendas.
- Los estacionamientos es de acuerdo al uso de vivienda.
Se establece la modalidad "park and ride" (intermodal) estableciendo redes de transporte público, privado y edificios de estacionamiento.

$\begin{aligned} & \text { edificios de estacionamiento. } \\ & \text { Además se establece la aplicación de limitaciones en }\end{aligned}$ tiempos de parqueo y el fomento de utilización de bicicletas.
La tendencia es priorizar el uso del transporte público y movilidad alternativa, restringir los estacionamientos de acuerdo al área de vivienda e inclusive a
la cantidad de viviendas proyectadas
Mitigar los riesgos en los inmuebles a través del reforzamiento de las edificaciones Se implementa el programa de revisión y los inmuebles.

Supresión progresiva del cableado aéreo

y la revisión exhaustiva de instalaciones interiores de los inmuebles.

\section{Las construcciones nuevas deberán cumplir las medidas que en orden a la proteccion contra incen- dios, establecen la Norm Básica de la Edificación Las construcciones exis- tentes deberán adecuars a la reglamentación de proteccion contra incen- dios, en la medida máxima funcionamiento
funcen}

Se asignan instalaciones que sirvan de refugio en caso de sismo o inundaciones debido a la cercanía con el mar. to declaran finca ruinosa aquellas edificaciones cuyo cosación es superior al $75 \%$ al valor En edificaciones nuevas que contemplen edificaciones de grado de protección de carácter ruinoso se considerará: su demolición si presenta una amenaza de derrumbe, su costo de recuperación es desproporcionado pero si su fachada es valiosa se debe reconstruir y adecuar a la obra nueva. Todo argumento para demoler debe ser expresado fotográficamente.

Grado de Protección III y IV (valor monumental y entorno) se demolerá si presenta amenaza de derrumbe y costo desproporcionado.
En el centro histórico de México se impulsa el uso mixto implementado la vivienda como uso principal, asimismo se plantea el incremento de alturas restringiéndola de acuerdo al contexto. Los estacionamientos y el área libre están condicionados a la cantidad de vivien
El centro histórico de Ecuador, tiene tres ejes vocacionales, en los cuales se incentiva el uso mixto y el incremento de la densidad pobobre pasar dos niveles, asimismo incentiva
sobionalidas a a mantener la tipología vivienda-patio. Los estacionamientos están restringidos al áre de cada vivienda.
El centro histórico de Cartagena de Indias, propone incrementar la altura de la edificación siempre y cuando el volumen $3 \mathrm{mts}$ ( por piso a construir). Se plantea mantener la tipología de los patios cuyo

El centro histórico de la Habana impulsa la densidad habitacional mediante el incremento de viviendas y el incremento de altura.

El volumen posterior se encontrará $2.75 \mathrm{~m}$ desde la

El área mínima de vivienda es de $45 \mathrm{~m}^{2}$. El área libre esta condicionada al COS. Se prioriza el transporte público. 
Se modificó de esta manera el ratio establecido por la Ordenanza 893-MML (2005), que señala un estacionamiento por cada cuatro viviendas para todo el Centro Histórico de Lima. En este punto es necesario reflexionar acerca de la casuística internacional, donde los estacionamientos corresponden directamente al área de vivienda y donde la tendencia es descongestionar de vehículos el interior de los centros históricos; esto fomenta el uso del sistema de transporte público y de la bicicleta. Al respecto, citamos el artículo 12.3 del Reglamento Especial de Habilitación Urbana y Edificación, para el fondo MIVIVIENDA S.A., aprobado por el Ministerio de Vivienda, Construcción y Saneamiento (2013), que señala lo siguiente:

En el caso de proyectos de densificación urbana que transformen parcial o totalmente las viviendas unifamiliares existentes en bifamiliares o multifamiliares: ... c) No será exigible la provisión de estacionamientos, salvo que un estudio de demanda lo solicite, pudiéndose [sic] construir edificios o bolsas de estacionamientos.

Para el presente caso, entendemos la intervención como un conjunto residencial y no como un edificio multifamiliar, en el sentido estricto de la definición.

Tenemos la convicción de que debe ser prioritario evitar congestionar el convulsionado Centro Histórico de Lima con más vehículos; esto nuclea los accesos y salidas vehiculares de los estacionamientos, y concentra el número de espacios de estacionamientos para renta y para residentes (ver Figura 19).

Con respecto a la altura y volumen posterior, se propuso un retranque (con 7 a $10 \mathrm{~m}$ de profundidad) a partir del segundo nivel, con lo que se llegaría a una altura de tres o cuatro niveles (máximo 11.3 metros) que respeten el perfil del contexto inmediato. Solo en el Jr. Amazonas se incrementa la altura a seis pisos alineados al perfil, con lo que se respeta el fondo de crujía de los lotes (ver Figuras 20 y 21).

Definir la altura suscitó una constante discusión entre los diversos equipos técnicos participantes. La evaluación de la casuística internacional arrojó un promedio de entre cuatro y seis niveles; las posiciones más conservadoras optaron por no elevar las edificaciones a más de cuatro niveles. No obstante, estamos convencidos de que solo se dará cumplimiento a los Lineamientos Básicos Orientadores (L.B.O.) propuestos si se incrementa la altura.

La altura tiene relación directa con el área libre y la densidad: a mayor altura sobre un mismo suelo (terreno), mayor densificación habitacional. La manera de controlar esta densidad es incrementar el área libre. Entonces, si queremos recuperar el carácter de barrio y procurar mejorar la calidad de vida de sus habitantes, se requiere densificar las edificaciones con mayores alturas, de cinco y seis niveles en la manzana 6007, y de cuatro y cinco niveles en la manzana 6016. Esto se podría lograr a través del uso de retranques sucesivos con frente a las vías, que respeten la monumentalidad del contexto y refuercen el perfil preexistente. Se ha considerado respetar la densidad neta máxima de 2250 hab./ha, establecida en el Decreto Supremo 013-2013-VIVIENDA; aclaramos que la Ordenanza 893-MML (2005) vigente no limita la densidad, lo que ocasiona la tugurización de edificaciones nuevas. De esta manera se podría incrementar el área libre entre $35 \%$ y $40 \%$, lo que favorecería las dinámicas activas y pasivas para el área social en el interior del conjunto residencial, y evocaría la tipología de vivienda-patio tradicional.

La propuesta consideró una densidad promedio de 1900 hab./ha, una población total de 10,313 habitantes, lo que incluye 2580 hab. para renovación urbana (25\%) y 30\% de área libre. El área verde se estableció en $1 \mathrm{~m}^{2}$ por persona; se utilizarían los retranques propuestos de los volúmenes posteriores como techos verdes y soluciones alternativas para la configuración del área verde en el nivel de acceso. Esto ocuparía 51.27\% del área libre. Se opta por incentivar la recuperación de las áreas verdes para disfrute de los pobladores de Barrios Altos, que solo se ubican en el interior de conventos o patios de iglesias. 
devenir Vol. 3, N5, ENERO- JUNIO 2016, PP. 67-89 - ESTUDIOS I ISSN 2312-7570

UNIVERSIDAD NACIONAL DE INGENIERÍ, LIMA
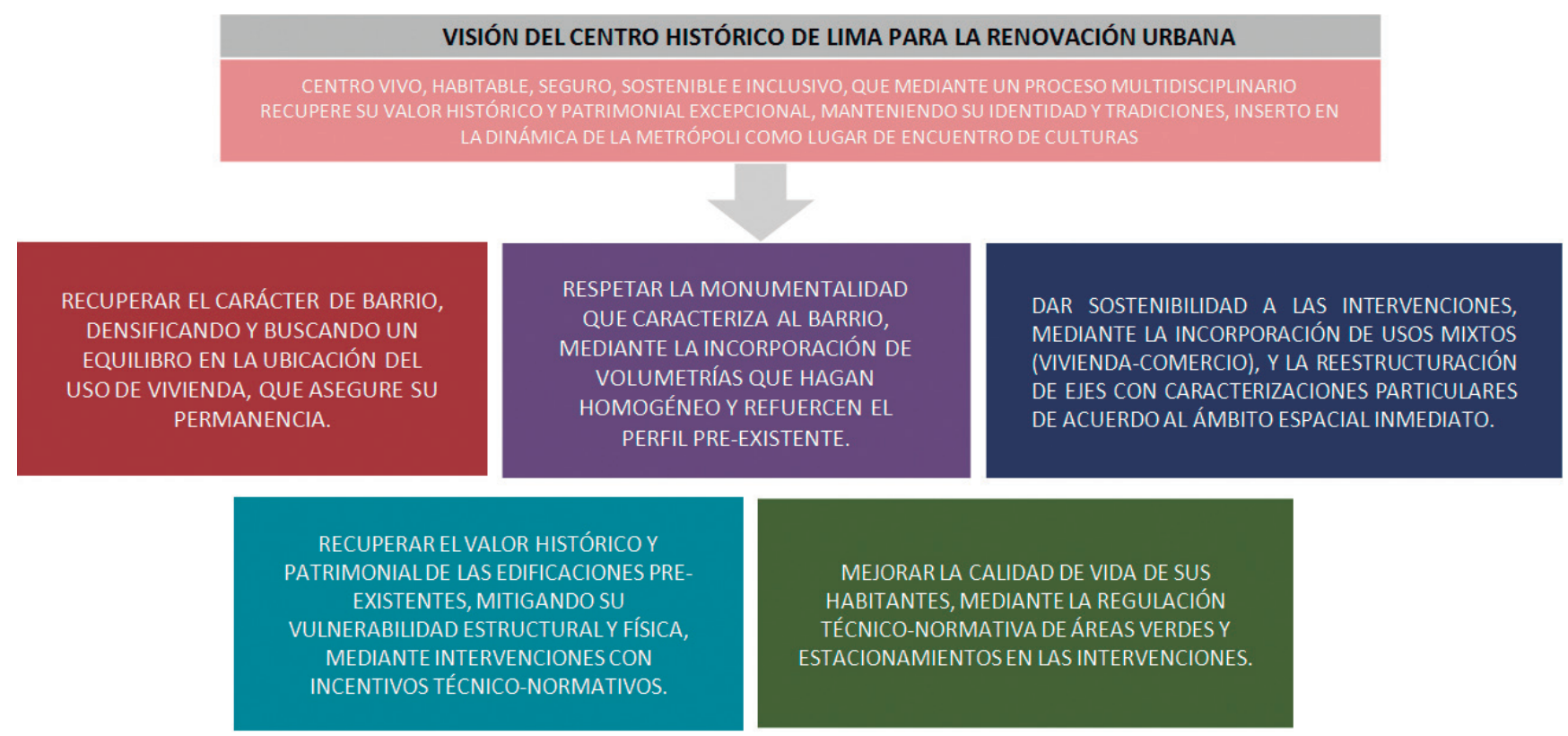

Figura 18. Visión y LBO

Fuente: Propuesta de lineamientos básicos orientadores (L.B.O.) técnicos para áreas de tratamiento con fines de Renovación Urbana, 2014.
Es necesario elaborar mecanismos de gestión para lograr la autosostenibilidad de las áreas verdes en proyectos de renovación urbana dirigidos a pobladores de diversos niveles socioeconómicos (ver Figuras 22 y 23), así como contrarrestar la diversidad de usos de carácter incompatible y no autorizados, tales como depósitos y otras industrias, que degradan los predios y los ambientes urbanos monumentales.

La propuesta da sostenibilidad a las intervenciones mediante el uso mixto (vivienda-comercio) en el primer nivel de las edificaciones, lo que además crea la dinámica requerida por el carácter residencial y proporciona un carácter de integralidad funcional a la propuesta.

Concordamos en la definición de tres ejes potenciales de uso mixto que consolidan la ubicación privilegiada de las manzanas 6007 y 6016.

Eje 1 - Comercio local. Recupera el Jr. Huanta, el Jr. Jauja y el Jr. Huánuco con actividades comerciales destinadas al uso de los residentes, como bazares, bodegas, locales de comida rápida, cafeterías y minimarkets.

Eje 2 - Comercio y recreación cultural. Recupera el ambiente urbano monumental del Jr. Ancash mediante la inserción del valor turístico cultural con equipamiento: hospedajes en las casonas, galerías de arte, cafés, venta de artesanías y restaurantes turísticos.

Eje 3 - Comercio especializado. Recupera el Jr. Amazonas con el refuerzo del carácter cultural especializado, como el caso de las librerías-café y librerías especializadas, así como con la inserción de comercios de mayor envergadura, como hospedajes.

Finalmente, en las intervenciones de inserción de vivienda se propone un mayor equilibrio y diversificación de estas, como la vivienda alquiler; la vivienda para artistas (estudio), para los jóvenes profesionales y comerciantes (población flotante); y la vivienda multifamiliar para renovación urbana. Se espera que estas contribuyan a consolidar un Centro Histórico vivo que albergue múltiples culturas, identificadas como una sola comunidad (ver Figuras 24 y 25 ). 


\section{Conclusiones}

\section{A nivel general y reflexivo}

1. El análisis histórico sobre los cambios físicos externos e internos, que considera diversos esquemas de crecimiento según su temporalidad, espacialidad y conectividad, ha permitido definir cualitativamente la intensidad del cambio morfológico durante cada periodo. Barrios Altos, como unidad espacial, ha sufrido una serie de transformaciones morfológicas vinculadas a sus periodos históricos. Entre ellas, se encuentra ser un espacio de transición o de desplazamiento, el cambio de superficie rural a urbano, el aumento de densidad en el interior de la manzana y los usos de suelos heterogéneos donde la vivienda siempre es el aspecto más importante. Esto ayuda a comprender las consideraciones previas más importantes de origen y consolidación que han sufrido las manzanas aquí estudiadas.

2. Es de gran importancia comprender que la renovación urbana desde la gestión municipal no es un plan de destugurización bajo una normatividad específica ni un paquete de intervenciones físicas aisladas en el espacio público. Tampoco se puede priorizar únicamente el rescate de los valores monumentales y mucho menos generar interacciones socioculturales, por más bien intencionadas que estas sean. La renovación urbana debe ser asumida como un proceso de ideas y acciones a mediano y largo plazo -de voluntad política sostenida-, con una mirada integradora donde todas las dimensiones sean manejadas disciplinariamente a través de nuevos enfoques y estrategias que tengan como objetivo principal la mejora de la calidad de vida del poblador original de Barrios Altos.

3. En función a la experiencia y las propuestas de ensayo-error dadas a nivel latinoamericano, se conoce que los procesos de renovación urbana en Centros Históricos, por su multidimensionalidad, son procesos lentos, largos y llenos de variables sorpresa; tan solo con participaciones parciales o asumidas desde la gestión municipal no es suficiente y ni siquiera alentador. Por ello, una alternativa es plantear tres modelos de gestión en renovación urbana y destugurización: primero, el modelo de i) renovación urbana desde una visión tradicional del Estado; luego, ii) renovación urbana focalizada en el mercado inmobiliario, en paralelo con un modelo de renovación urbana con una intervención institucionalista; y, finalmente, iii) renovación urbana de necesidad pública, preferentemente de interés social -estos deberán diseñarse y planificarse específicamente teniendo en cuenta la realidad del Cercado de Lima-.

4. La reconfiguración morfológica de estas manzanas y de Barrios Altos en su conjunto debe convertirse en objetivo de emergencia y no solo un debate dentro de la academia. Esta es una perfecta oportunidad, a manera de punto de inicio, para la construcción urbana del barrio con mejores condiciones de vida, el fortalecimiento de sus economías locales, la regulación de sus dinámicas internas, y la conservación de su escala barrial dentro de la normatividad vigente nacional y metropolitana.

5. Existen limitaciones de origen en cuanto a las funciones y el rol que debe desempeñar la Subgerencia de Renovación Urbana (SRU) de la MML, ya que esta se centra principalmente en viabilizar y salvar los aspectos operativos de una ley especifica que busca principalmente minimizar el número de tugurios en Barrios Altos.

6. En cuanto a la autoridad edil, si bien el objetivo fue proyectar una visión concertada con un enfoque multidisciplinario, en la práctica se verificó que las políticas laborales de diversas dependencias fluctúan entre el recelo por compartir información y un sentido de lograr objetivos aislados que contribuyan a su propio bienestar, a pesar de su condición de servidores públicos.

\section{A nivel específico y propositivo}

1. A pesar de desarrollar el análisis y procesamiento de la información socioeconómica y técnica, una parte importante de este proceso integral no se pudo desarrollar: las ac-

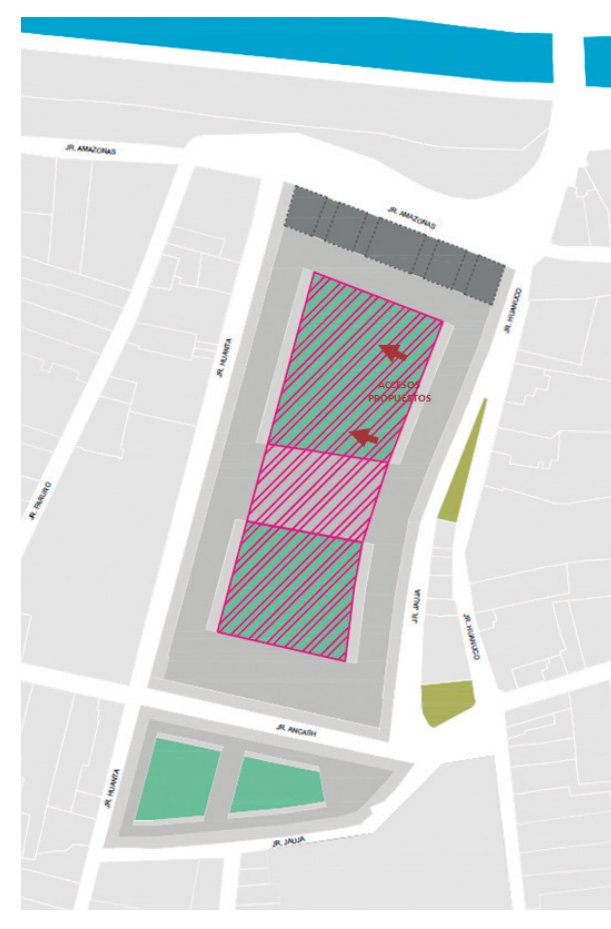

Figura 19. Propuesta de estacionamientos

Fuente: Propuesta de lineamientos básicos orientadores (L.B.O.) técnicos para áreas de tratamiento con fines de Renovación Urbana, 2014. 


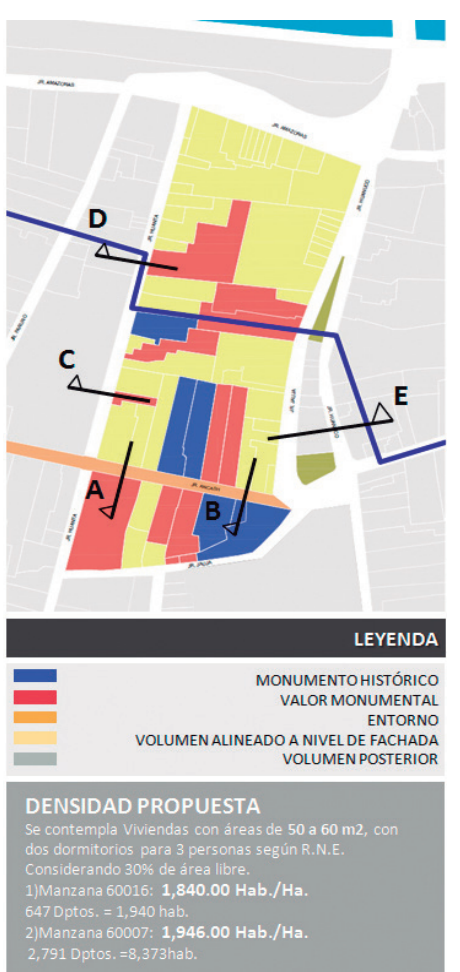

Figuras 20 y 21. Propuesta de alturas Fuente: Propuesta de lineamientos básicos orientadores (L.B.O.) técnicos para áreas de tratamiento con fines de Renovación Urbana, 2014.

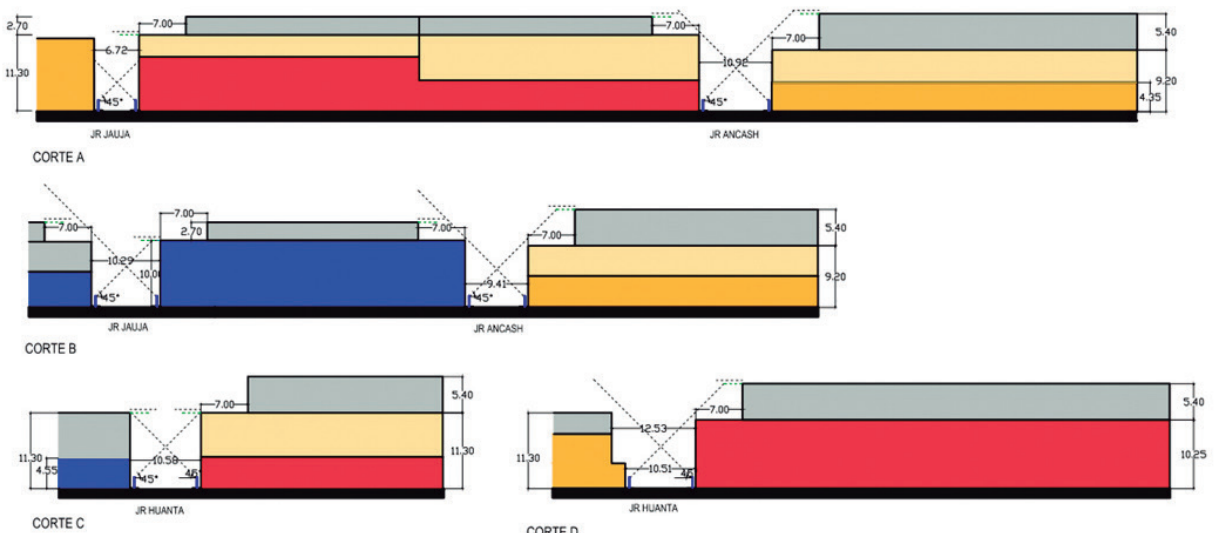

CORTED
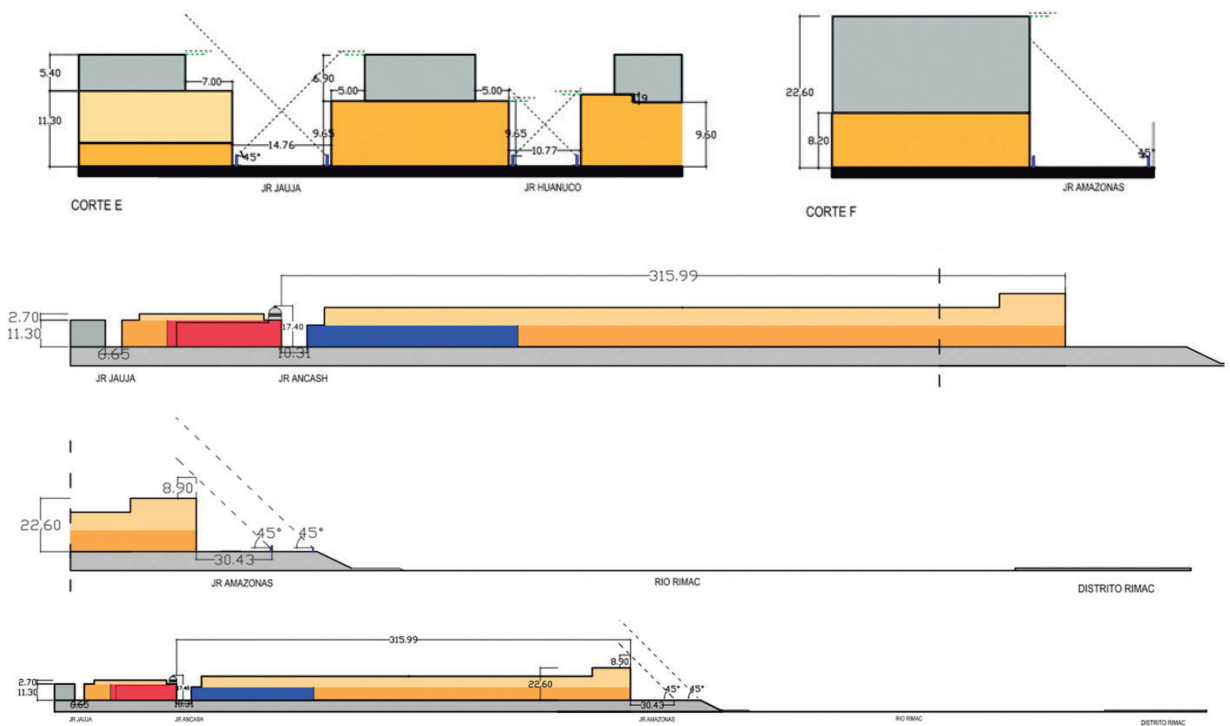

ciones pertinentes para la aplicación de los lineamientos, y parámetros urbanísticos y edificatorios planteados. Es decir, no se pudo elaborar un instrumento de gestión que coordine la participación de los diversos actores y oriente el proceder, para la correcta participación e intervención activa entre el sector público y el privado.

2. Otro factor importante que no permite monitorear el estado de base en Barrios Altos es la falta de una base de datos y catastro depurados o actualizados; solo se cuenta con diagnósticos aislados de análisis interdisciplinarios, donde cada análisis busca abordar diferentes interpretaciones, y luego se obtiene una sumatoria de datos e información. Incluso existe duplicidad de información, objetivos e inversión pública.

3. La presente propuesta tuvo la virtud de afinar los lineamientos técnicos y materializarlos a nivel de parámetros urbanísticos y edificatorios, los cuales otorgan seguridad jurídica e incentivan la inversión privada o mixta (público-privada) en una zona de alta degradación como Barrios Altos. Se optó por analizar y reflexionar sobre la casuística internacional, que marca una referencia tangible de casos exitosos ejecutados en realidades similares a la nuestra, y por considerar los planes en desarrollo para el Centro Histórico de Lima en el año 2014, lo que representó una iniciativa por conciliar la mayor cantidad de información técnica de calidad disponible.

4. Si bien es necesario considerar un ratio de estacionamiento mínimo para las viviendas y el comercio, debe ser prioritario evitar congestionar el convulsionado Centro 
Renovación uRbana y Centro Histórico de Lima: Reflexiones sobre aspectos técnicos en la ReConfiguraCión morfológica de las manzanas 6007 y 6016 de BarRios Altos

Antonio Álvarez Reátegui y Fredy Mendoza Núñez
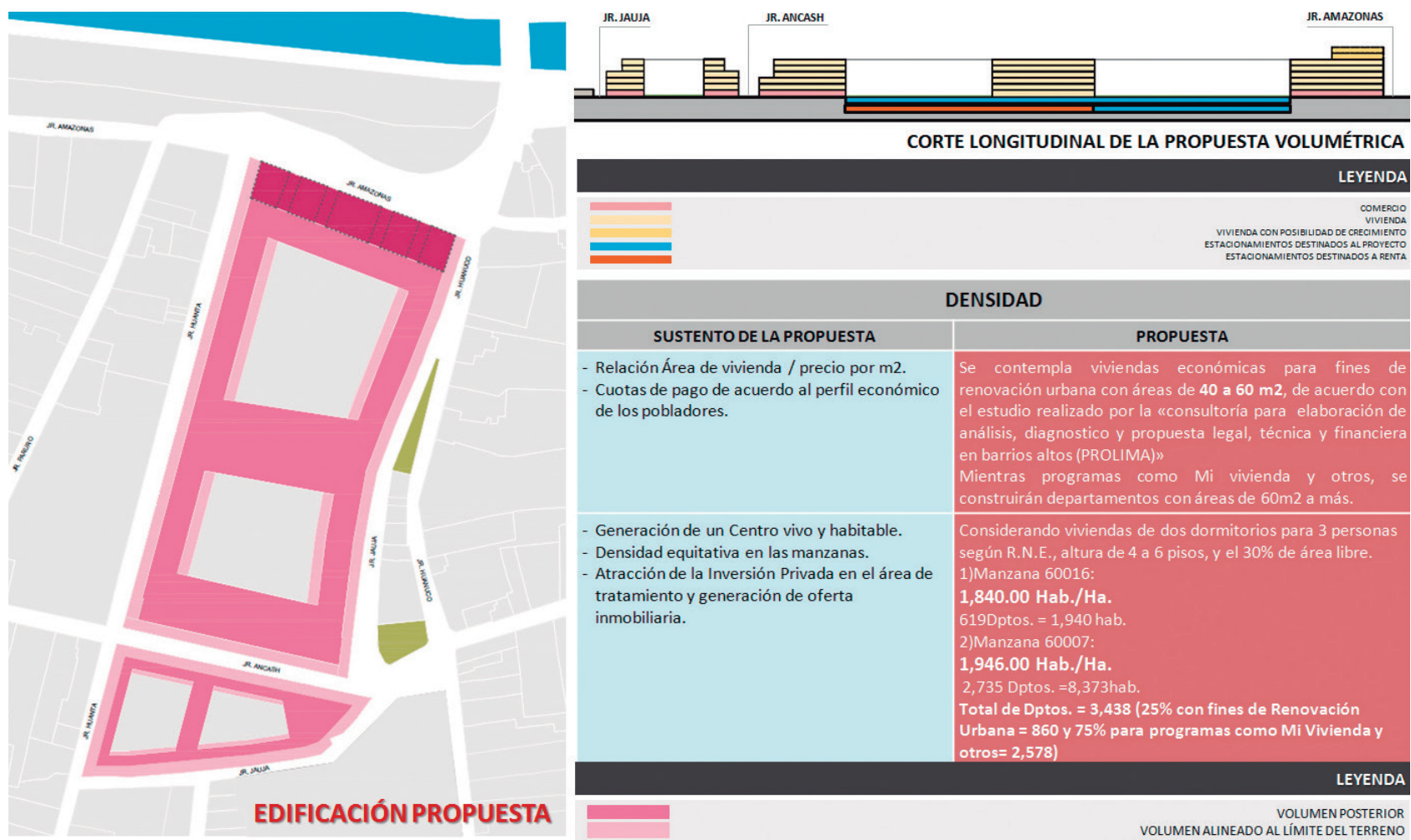

CORTE LONGITUDINAL DE LA PROPUESTA VOLUMÉTRICA

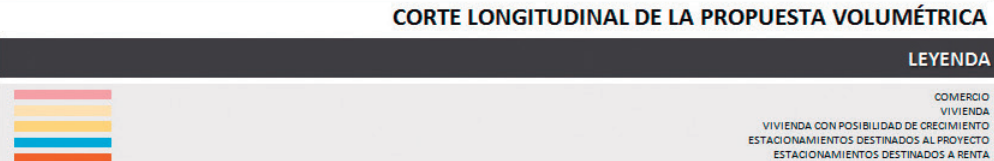

\begin{tabular}{|c|c|}
\hline \multicolumn{2}{|c|}{ DENSIDAD } \\
\hline SUSTENTO DE LA PROPUESTA & PROPUESTA \\
\hline $\begin{array}{l}\text { - Relación Área de vivienda / precio por m2. } \\
\text { - Cuotas de pago de acuerdo al perfil económico } \\
\text { de los pobladores. }\end{array}$ & $\begin{array}{l}\text { Se contempla viviendas económicas para fines de } \\
\text { renovación urbana con áreas de } 40 \text { a } 60 \mathrm{~m} 2 \text {, de acuerdo con } \\
\text { el estudio realizado por la «consultoría para elaboración de } \\
\text { análisis, diagnostico y propuesta legal, técnica y financiera } \\
\text { en barrios altos (PROLIMA)» } \\
\text { Mientras programas como Mi vivienda y otros, se } \\
\text { construirán departamentos conáreas de } 60 \mathrm{~m} 2 \text { a más. }\end{array}$ \\
\hline $\begin{array}{l}\text { - Generación de un Centro vivo y habitable. } \\
\text { - Densidad equitativa en las manzanas. } \\
\text { - Atracción de la Inversión Privada en el área de } \\
\text { tratamiento y generación de oferta } \\
\text { inmobiliaria. }\end{array}$ & $\begin{array}{l}\text { Considerando viviendas de dos dormitorios para } 3 \text { personas } \\
\text { según R.N.E., altura de } 4 \text { a } 6 \text { pisos, } y \text { el } 30 \% \text { de área libre. } \\
\text { 1)Manzana } 60016: \\
\text { 1,840.00 Hab./Ha. } \\
\text { 619Dptos. }=1,940 \text { hab. } \\
\text { 2) Manzana } 60007 \text { : } \\
\text { 1,946.00 Hab./Ha. } \\
\text { 2,735 Dptos. }=8,373 \text { hab. } \\
\text { Total de Dptos. }=3,438 \text { ( } 25 \% \text { con fines de Renovación } \\
\text { Urbana }=860 \text { y } 75 \% \text { para programas como Mi Vivienda y } \\
\text { otros }=2,578 \text { ) }\end{array}$ \\
\hline & LEYENDA \\
\hline & $\begin{array}{l}\text { VOLUMEN POSTERIOR } \\
\text { VOLUMEN ALINEADO AL LIMITEDEL TERRENO } \\
\text { VOLUMEN CON POSIBILIDAD DECRECIMIENTO }\end{array}$ \\
\hline
\end{tabular}

Figura 22. Propuesta densidad

Fuente: Propuesta de lineamientos básicos orientadores (L.B.O.) técnicos para áreas de tratamiento con fines de Renovación Urbana, 2014.
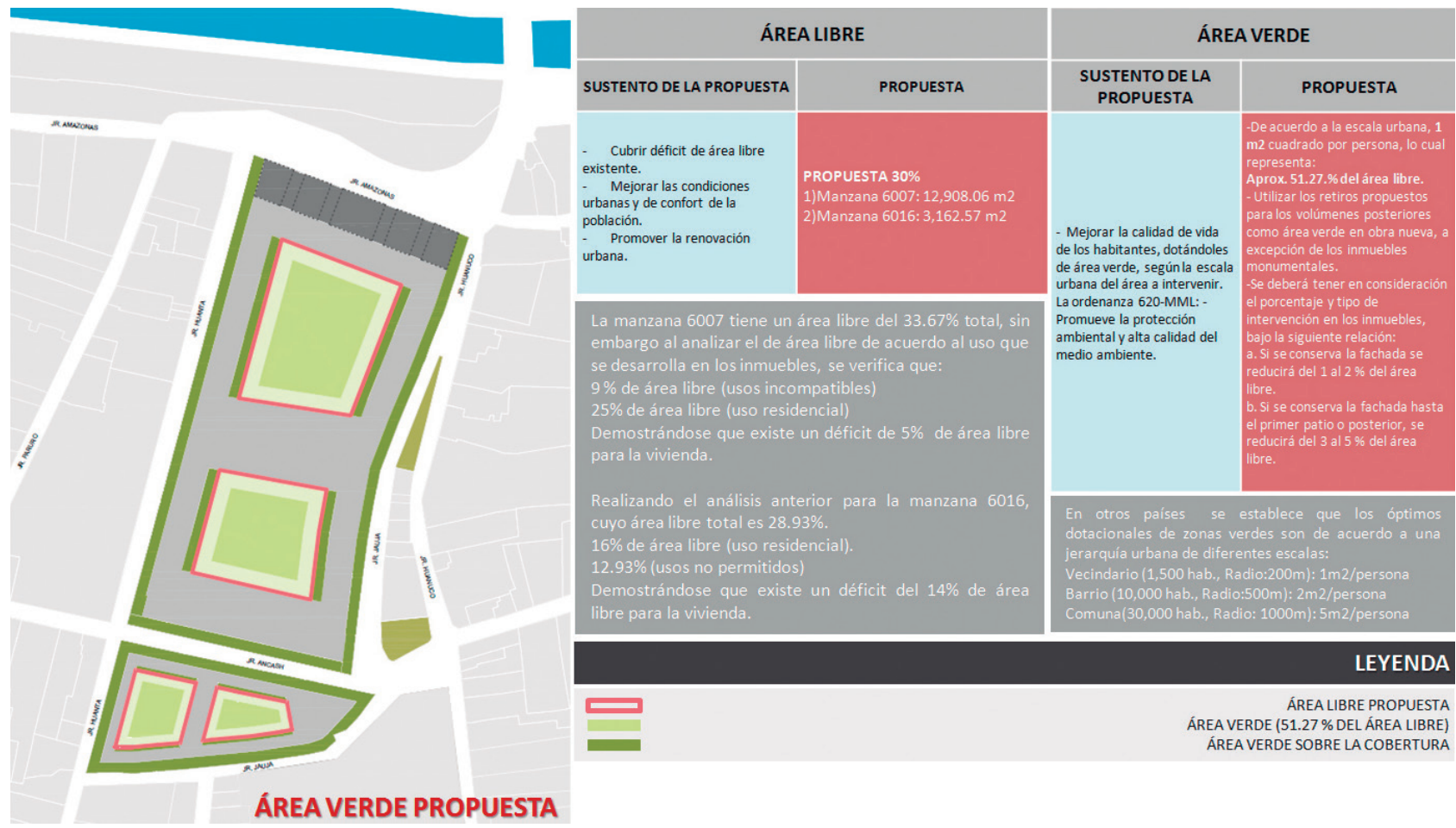

LEYENDA

ÁREA LIBRE PROPUESTA AREA LIBRE ṔRE LESTA
ÁREA VERDE (51.27\% DEL ÁREA LIBRE) ÁREA VERDE SOBRE LA COBERTURA

Figura 23. Propuesta área libre

Fuente: Propuesta de lineamientos básicos orientadores (L.B.O.) técnicos para áreas de tratamiento con fines de Renovación Urbana, 2014. 
devenir Vol. 3, N5, ENERO- JUNIO 2016, PP. 67-89 - ESTUDIOS I ISSN 2312-7570

UNIVERSIDAD NACIONAL DE INGENIERÍA, LIMA
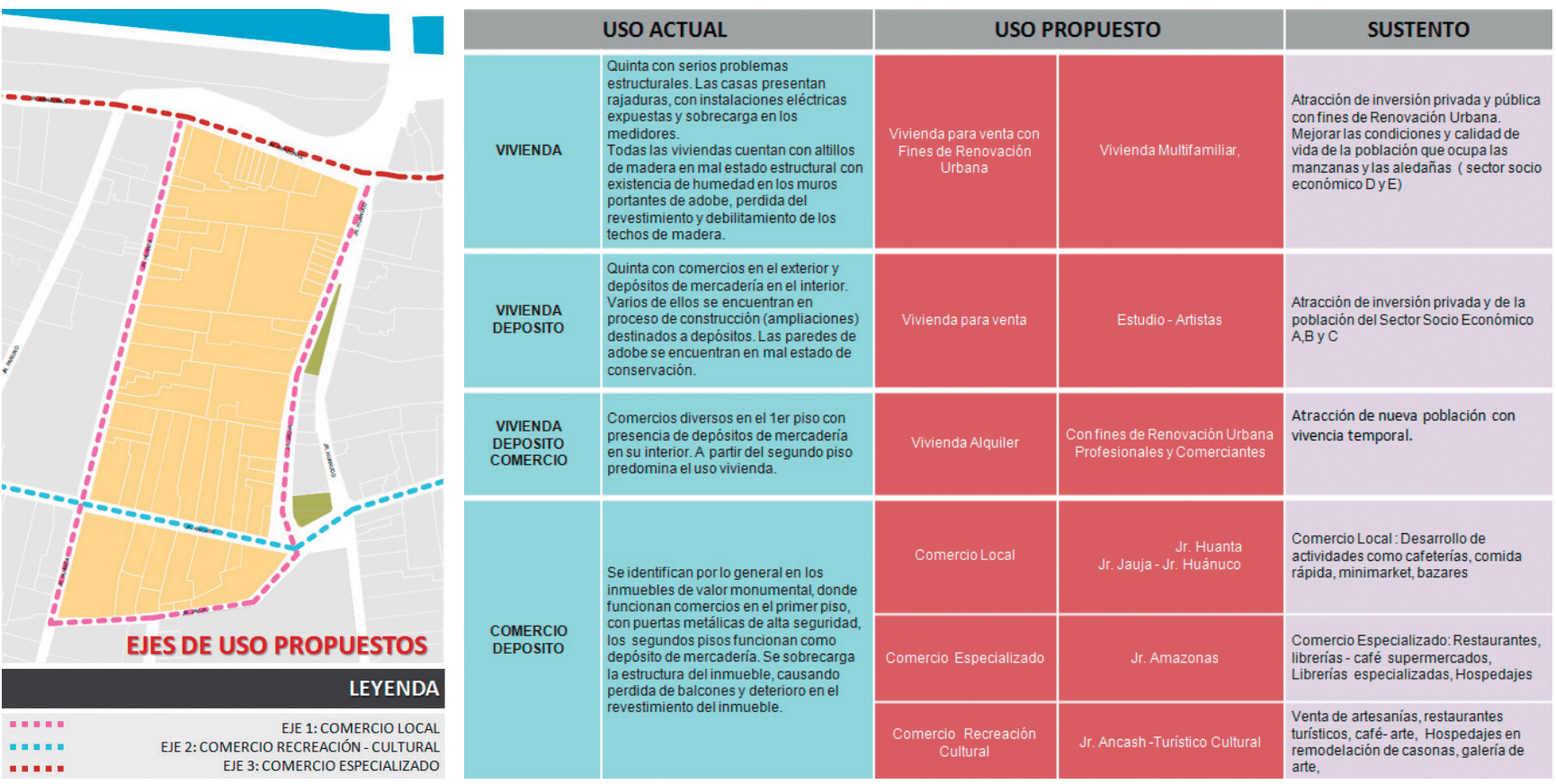

Figura 24. Propuesta Usos

Fuente: Propuesta de lineamientos básicos orientadores (L.B.O.) técnicos para áreas de tratamiento con fines de Renovación Urbana, 2014.

Figura 25. Vista volumétrica de la propuesta

Fuente: Propuesta de lineamientos básicos orientadores (L.B.O.) técnicos para áreas de tratamiento con fines de Renovación Urbana, 2014.

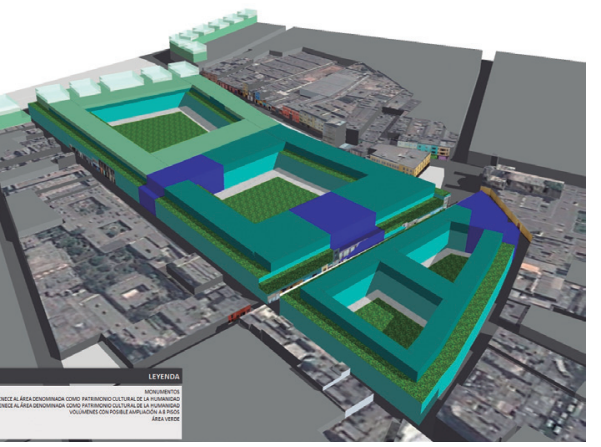

Histórico de Lima con más vehículos; para el presente caso se nuclean los accesos y salidas vehiculares de los estacionamientos. Se incluyó la modalidad de renta de 414 espacios de estacionamiento para el área comercial del entorno inmediato; de esta manera se haría autosostenible la inversión inmobiliaria.

5. Para recuperar el carácter de barrio, se requiere densificar las edificaciones con alturas de cinco y seis niveles en la manzana 6007, y de cuatro y cinco niveles en la manzana 6016; el mecanismo sería el uso de retranques sucesivos con frente a las vías, que respeten la monumentalidad del contexto y refuercen el perfil preexistente. Se respetaría la densidad neta máxima de 2.50 hab./ha. De esta manera, se podría incrementar el área libre entre $35 \%$ y $40 \%$, lo que favorecería las dinámicas activas y pasivas para el área social en el interior del conjunto residencial, y evocaría la tipología de vivienda-patio tradicional.

6. Es importante incorporar la propuesta de $1 \mathrm{~m}^{2}$ de área verde por persona, y utilizar también los retranques propuestos para los volúmenes posteriores (techos verdes) y soluciones alternativas para la configuración de áreas verdes en $50 \%$ del área libre. Se incentivaría la recuperación de estas áreas para disfrute de los pobladores de Barrios Altos, que actualmente solo se ubican en el interior de conventos o patios de iglesias.

7. Se requiere dar sostenibilidad a las intervenciones mediante el uso mixto (vivienda-comercio) en el primer nivel de las edificaciones, lo que crea además la dinámica requerida por el carácter residencial. Concordamos en la definición de tres ejes potenciales de uso mixto que consolidan la ubicación privilegiada de las manzanas 6007 y 6016.

\section{Referencias}

Chueca, G. F. (1968). Breve historia del urbanismo. Madrid, España: Alianza.

Congreso de la República del Perú Gobierno del Perú PROLIMA. (2014). Propuesta de alturas para la manzana 6007 y 6016. Lima, Perú: PROLIMA.

De los Ríos, S. (2007). Conceptos de procesos y acciones para tener centros vivos en las ciudades. Revista Electrónica Serie Ciudad y Hábitat N 12, 67-85. 
Decreto Legislativo N 696. Ley de Promoción a la Inversión Privada en acciones de Renovación Urbana, Diario Oficial El Peruano. Lima, Perú, 05 de noviembre de 1991.

Decreto Supremo Nº 011- 2010- VIVIENDA. Ley de Saneamiento Fisico Legal de Predios Tugurizados con Fines de Renovacion Urbana. Lima, Perú, 30 de Octubre del 2010.

Decreto Supremo № 011- MTC. Diario Oficial El Peruano. Lima, Perú, 24 de julio de 1995.

Decreto Supremo № 013-2013. Reglamento Especial de Habilitación Urbana y Edificación, Diario Oficial El Peruano. Lima, Perú, 12 de octubre de 2013.

García Bryce, J. (1980). La Arquitectura del Virreinato y la República. Lima, Perú: Juan Mejía Baca.

Gerencia de Desarrollo Urbano. (2014). Propuesta del Plan Concertado del Cercado de Lima. Lima, Perú: Municipalidad Metropolitana de Lima.

Gunther, D. J. (1983). Planos de Lima 1613 - 1983. Recuperado de https://www.academia. edu/11991716/Planos_de_Lima_1613_1983_Juan_Gunther_Doering

Ley N ํ2ㄴ 29415. Ley de Saneamiento Físico Legal de predios tugurizados con fines de renovación urbana, Diario Oficial El Peruano.Lima, Perú, 02 de octubre de 2009.

Ludeña, U. W. (2010). Lima y espacios públicos: perfiles y estadística integrada 2010. Lima, Perú: Pontificia Universidad Católica del Perú.

Mattos-Cardenas, L. (2004). Urbanismo andino e hispanomericano: Ideas ideas y realizaciones (1530-1830). Lima, Perú: Fondo Editorial FAUA.

Menenghello, J. (1972). Pediatría (Vol. 1). Buenos Aires, Argentina: Inter-Médica.

Ministerio de Vivienda. Reglamento Nacional de Edificaciones, Diario Oficial El Peruano. Lima, Perú, 08 de junio de 2006.

Municipalidad Metropolitana de Lima. (2014). Propuesta de lineamientos basicosbásicos orientadores (L.B.O.) tecnicostécnicos para areasáreas de tratamiento con fines de Renovación Urbana [Documento Final final y Diapositivas diapositivas de PowerPoint]. Recuperadas de archivo digital Subgerencia de Renovacion Urbana - Gerencia de Desarrollo Urbano / PROLIMA- MML.

Ordenanza Nº62- MML. Reglamento de la Administración del Centro Histórico de Lima. Lima, Perú, 18 de Agosto de 1994.

Ordenanza N 201- MML. Plan Maestro Centro de Lima, Diario Oficial El Peruano. Lima, Perú, 12 de abril de 1999.

Ordenanza №341- MML. Ordenanza de la Actualización del Sistema Vial Metropolitano de Lima, Diario Oficial El Peruano. Lima, Perú, 06 de diciembre de 2001.

Ordenanza N 893- MML. Reajuste Integral de la Zonificación de los Usos de Suelo del Cercado de Lima, Diario Oficial El Peruano. Lima, Perú, 27 de diciembre de 2005.

Orrego, P. J. (2009). Historia del Perú, América Latina y el mundo. Siglos XIX y XX: El río Huatica. Recuperado de http://blog.pucp.edu.pe/blog/juanluisorrego/2009/07/02/el-rio-huatica/

Ramón, J. G. (1999). La muralla y sus callejones. Lima, Perú: Sidea/Promperú.

Vargas, A. (2014). Consultoría de elaboración de análisis, diagnóstico y propuesta legal, técnica y financiera con fines de renovación urbana de una zona de Barrios Altos. Lima, Perú: Banco Interamericano de Desarrollo. 